Provided for non-commercial research and educational use only. Not for reproduction or distribution or commercial use.

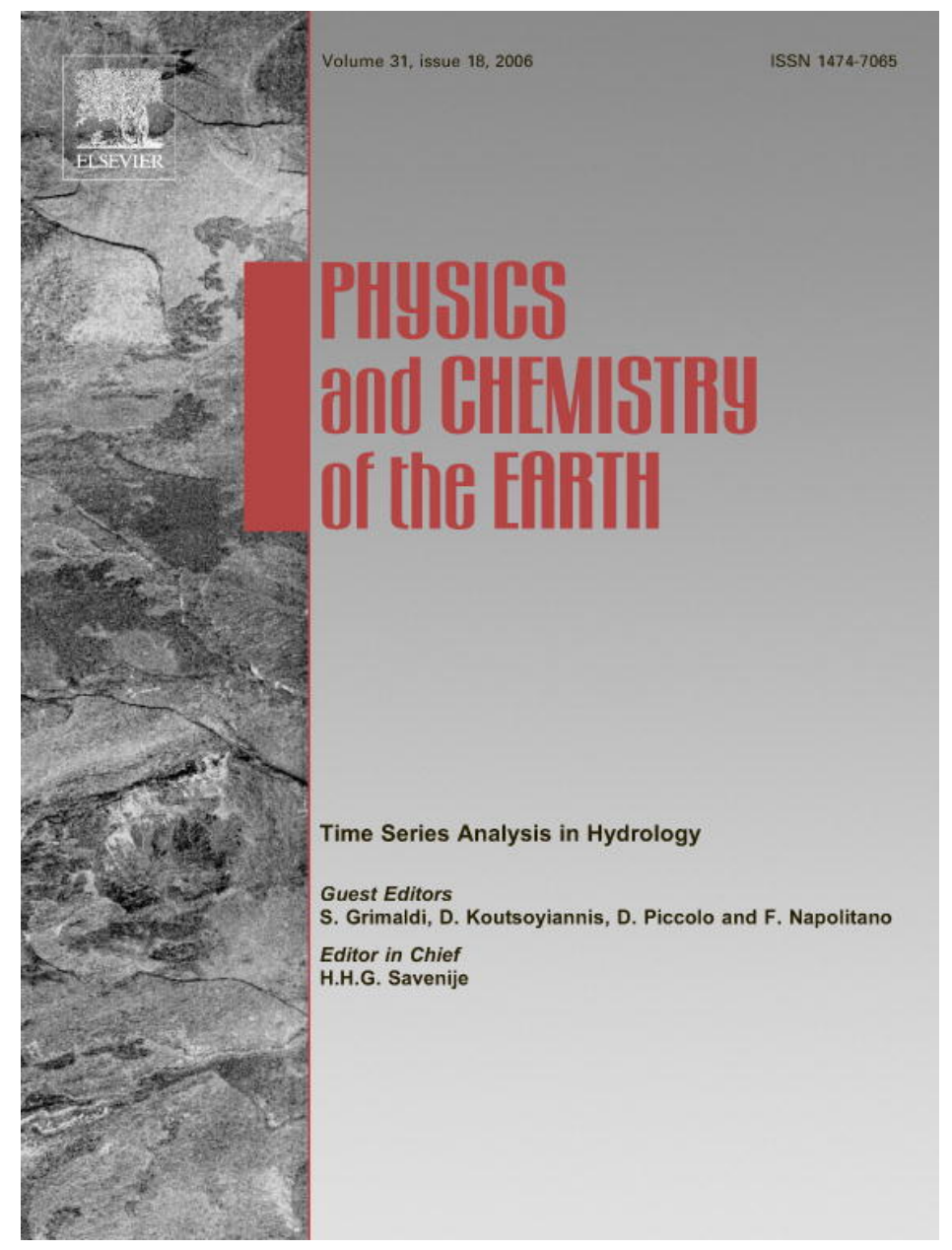

This article was originally published in a journal published by Elsevier, and the attached copy is provided by Elsevier for the author's benefit and for the benefit of the author's institution, for non-commercial research and educational use including without limitation use in instruction at your institution, sending it to specific colleagues that you know, and providing a copy to your institution's administrator.

All other uses, reproduction and distribution, including without limitation commercial reprints, selling or licensing copies or access,

or posting on open internet sites, your personal or institution's website or repository, are prohibited. For exceptions, permission may be sought for such use through Elsevier's permissions site at: 


\title{
Multi-year drought frequency analysis at multiple sites by operational hydrology - A comparison of methods
}

\author{
Claudio Arena, Marcella Cannarozzo *, Mario Rosario Mazzola \\ Dipartimento di Ingegneria Idraulica ed Applicazioni Ambientali, Viale delle Scienze Edificio 8, 90128 Palermo, Italy
}

Received 11 July 2005; received in revised form 13 March 2006; accepted 13 March 2006

\begin{abstract}
This paper compares two generators of yearly water availabilities from sources located at multiple sites with regard to their ability to reproduce the characteristics of historical critical periods and to provide reliable results in terms of the return period of critical sequences of different length. The two models are a novel multi-site Markov mixture model explicitly accounting for drought occurrences and a multivariate ARMA. In the case of the multisite Markov mixture model parameter estimation is limited to a search in the parameter space guided by the value of parameter $\lambda$ to show the sensitivity of the model to this parameter. Application to two of the longest time series of streamflows available in Sicily (Italy) shows that the models can provide quite different results in terms of estimated return periods of historic droughts, although they seem to perform more uniformly when it comes to simulate drought-related statistics such as drought length, severity and intensity. The role of parameter selection for the multisite Markov mixture model and of the marginal probability of generated flows in providing results consistent with the characteristics of the observed series is discussed. Both models are applied to the system of sources supplying the city of Palermo (Sicily) and its environs showing the applicability of the newly developed multisite Markov mixture model to medium-to-large scale water resources systems.
\end{abstract}

(C) 2006 Elsevier Ltd. All rights reserved.

Keywords: Droughts; Time series; Markov mixture model; ARMA model

\section{Introduction}

Owing to the growing pressure of civil and agricultural uses on water resources, multiyear droughts, i.e. periods lasting more than one year when the availability of water resources keeps constantly below the expected value, now raise concern on water planners and managers in many Mediterranean areas. As a natural phenomenon, they probably constitute the most severe test bench of the efficiency of a water resources system and are recognised by many as the real test bench in the planning and management of complex systems featuring regulated resources. Shortcomings in supply and distribution such as poor maintenance of the network with high level of losses or

\footnotetext{
${ }^{*}$ Corresponding author. Tel.: +3909 16657731; fax: +3909 16657749 .

E-mail address: marcella@idra.unipa.it (M. Cannarozzo).
}

unaware management of reservoirs and aquifers may not produce in normal or wet years any serious inconvenience to customers, but they will certainly do during prolonged dry periods. This is particularly true wherever the sustainability index, i.e. the ratio supply/demand is close to one, as in most Mediterranean countries. In these areas water resources systems supplying urban areas make frequently conjunctive use of surface and groundwater sources spread over large areas and often heavily rely on reservoirs. In such cases one year can be assumed as the significant time unit and droughts can be defined as those periods lasting an integer number of years, when average annual streamflow takes on values below a given threshold (Yevjevich, 1967; Dracup et al., 1980a,b). In this framework, drought frequency analysis allows to gain awareness of the extent of previous drought events in terms of duration and magnitude and helps predict the riskiest hydrologic situation from the standpoint of water supply. 
As illustrated in the following section, drought frequency analysis on multiple sites is often performed via operational hydrology. The first part of the paper is devoted to introducing a new generator of yearly flows explicitly accounting for drought occurrences: it is the extension to the multiple sites case of a Markov mixture model (Jackson, 1975) for yearly flow generation. The performances of such a model are compared to those of a multisite ARMA model, a well-established model widely employed in water resources planning and analysis.

\section{Previous work}

According to the definition of multiyear drought based on the theory of runs (Yevjevich, 1967; Dracup et al., 1980a,b), a drought event can be considered as consisting of three components: a duration $D$, a severity $S$, i.e. the sum over $D$ of deficits respect a given threshold, and a magnitude or intensity $M=S / D$. Based on this definition, both simulation studies have been carried out in order to fit probability distributions to drought parameters extracted from simulated series generated by a streamflow generation techniques (Millan and Jevjevich, 1971) and analytic distributions have been fitted directly to historical data to obtain the probability distribution of maximum drought duration and severity. Other approaches to multiyear drought frequency analysis based on the above definition include the application of multiple linear regression techniques to derive estimates of drought parameters using watershed and climatic information (Paulson et al., 1985) as well as the use of hazard-function models to reproduce the duration-dependent termination rate of a drought data set (Lee et al., 1986).

A noticeable extension of this approach to a region is that provided by Santos (1983) introducing two critical thresholds to define regional droughts: one for precipitation values and one for the drought-affected area. The author is hence able to provide a complete stochastic characterisation of meteorological (i.e. concerning precipitation) regional droughts by deriving the probability distribution of a number of drought-related parameters that take account of the areal extent of the drought phenomenon. The results of Santos (1983) may be in principle applicable to hydrologic drought frequency analysis. When considering streamflow, however, considerable difficulties are encountered. This is due not only to the limiting assumptions on the variable under study, but chiefly to the nature of the flow process which is discrete over space, being the watershed the discretization unit. Therefore, simulation by operational hydrology seems to be one of the few viable paths to perform risk assessments connected to hydrologic droughts at multiple sites.

However, drought frequency analysis has also been carried out following a different strategy, i.e. ignoring the above definition of drought, using operational hydrology to reproduce the marginal distribution functions of flows or rainfall and subsequently analysing the simulated series to obtain information on dry periods. The works of Srikanthan and McMahon (1985) and Frevert et al. (1989) illustrate how frequency analysis of dry periods may be carried out on simulated series by either assessing the average values of the smallest $n$ year totals (being $n$ the drought length) contained in a number of replicates of length $N$ (being $N$ the return period) or by counting the number of occurrences of a flow below a specified level (the truncation threshold) over $1-n$ years interval. The average of occurrences over the generated series provides an estimate of the non exceedance probability of a given flow level.

Ever since its coming to light, operational hydrology has been used as a tool for frequency analysis. The paper of Srikanthan and McMahon (2001) contains a review of models available up to date for the generation of synthetic yearly flows. The family of ARMA models has been widely used for such purpose, as well as different types of Markov models. Their applications in hydrology at all time scales are countless and it would be impossible to report them. Their underlying conceptual basis at yearly scale has been investigated, among the others, by Salas and Obeysekera (1992) and by Claps et al. (1993). In particular, Claps et al. (1993) consider runoff as generated by a linear system featuring two parallel linear reservoirs (one for the groundwater component with over-year response lag and one for the subannual component) and a zero-lag linear channel. Input to the system is the effective rainfall. Two models for yearly flows are compatible with such a conceptual model of runoff: a white noise for ephemeral streams with no groundwater component from previous years and an $\operatorname{ARMA}(1,1)$ model for streams for which such a groundwater component is significant. The seasonal streamflow models consistent therewith are a PIR-ARMA $(1,1)$ (periodic independent residual ARMA) model and a PIR$\operatorname{ARMA}(2,2)$ model, respectively.

More recently Thyer and Kuczera (2000) focused on the long-term persistence of dry and normal years and the need for explicitly incorporating such alternation in generation models, and highlighted this as a consequence of the specific climatic features of certain areas of the world where the interaction of global climatic mechanisms produces alternating wet and dry regimes in hydroclimatic time series. Thyer and Kuczera (2003a,b) have also proposed an extension to the multi-site case of the hidden state Markov model for modelling long-term persistence in precipitation records. In the Mediterranean, some kind of dependence between ENSO (El Nino Southern Oscillation) and interannual climatic variability has been highlighted (Mariotti et al., 2002) and this may constitute a further motivation for basing yearly generation techniques on models explicitly allowing for the alternation of dry and normal years.

\section{A space-time model for drought occurrences}

The simplest way to take droughts explicitly into account when modelling yearly flows is to classify years either as normal or as dry. The alternation of dry and 
normal years can therefore be viewed as a two-state binary process in which a dry year represents a failure (state 1) and a normal year a success (state 0). Concerning the form of such a process, a two-state homogeneous Markov chain with transition probabilities $a$ (from dry to normal years) and $b$ (from normal to dry years) has been proposed by Jackson (1975) and Gottschalk (1976) and it is an underlying assumption in probabilistic models proposed of maximum drought duration and severity (Güven, 1983). More recently, Thyer and Kuczera (2000) propose a hidden state Markov process to generate hydroclimatic time series with long-term persistence.

State transition probability $b$ from normal to dry years is not independent of $a$, rather it is linked thereto by

$b=\lambda /(1-\lambda) * a$

where $\lambda$ is the steady-state probability that the process is in state 1. It is equivalent (Benjamin and Cornell, 1970) to the fraction of years in which the process is in state 1 . Persistence dictates that $a+b<1$. The larger the value of $a+b$, the closer are annual flows to independence: $a$ is in fact linked to the first-order serial correlation coefficient $\rho_{1}$ as illustrated in Section 5.

Let now $s_{i}(i=1, \ldots, n)$ be a site where a supply source is located. Each supply source is characterised by a value of $a_{i}$ controlling the at site transition mechanism from dry to normal years or vice-versa. A simple space-time model for drought occurrences can be thought as being the sum of two independent binary processes, one allowing for the pairwise space dependence of the occurrence process of a normal/dry year at site $s X_{s, t}$ on the occurrence process $X_{k, t}$ of a normal/dry year at site $k$ (the "key" site for site s) over $N$ years, the other taking into account the characteristics of the transition mechanism at each site:

$X_{s, t}=V_{t} * X_{k, t}+\left(1-V_{t}\right) * U_{t}, \quad t=1, \ldots, N$

where $V_{t}$ is an independent binary process having Bernoulli marginal distribution with parameter $\gamma_{s k}$ and $U_{t}$ is a two state homogeneous Markov chain with transition probability $a_{i}$ and marginal distribution with parameter $\delta_{t}=\lambda$.

A model of this kind (a Discrete Autoregressive Process of order 1 in the time domain) has been used to model monthly streamflows for ephemeral streams featuring zero flows by Chebaane et al. (1995) and in the space domain by Straziuso et al. (1998) to model space dependence of zero monthly rainfall.

A model such as (2) for drought occurrences can be viewed as deriving from the following physical scheme: $V_{t}$ with its parameter $\gamma_{s k}$ regulates the space dependence of occurrences of dry and normal years between sites. Such a space correlation can be plausibly thought to be derived chiefly from a climatic homogeneity of the area, that is, space correlation of normal/dry years is controlled by rainfall. On the other hand, each site is characterised by a certain degree of persistence derived from each watershed's features, so that the final value of $X_{s, t}$ is the superposition of both effects. Such an interpretation of (2) may be appeal-

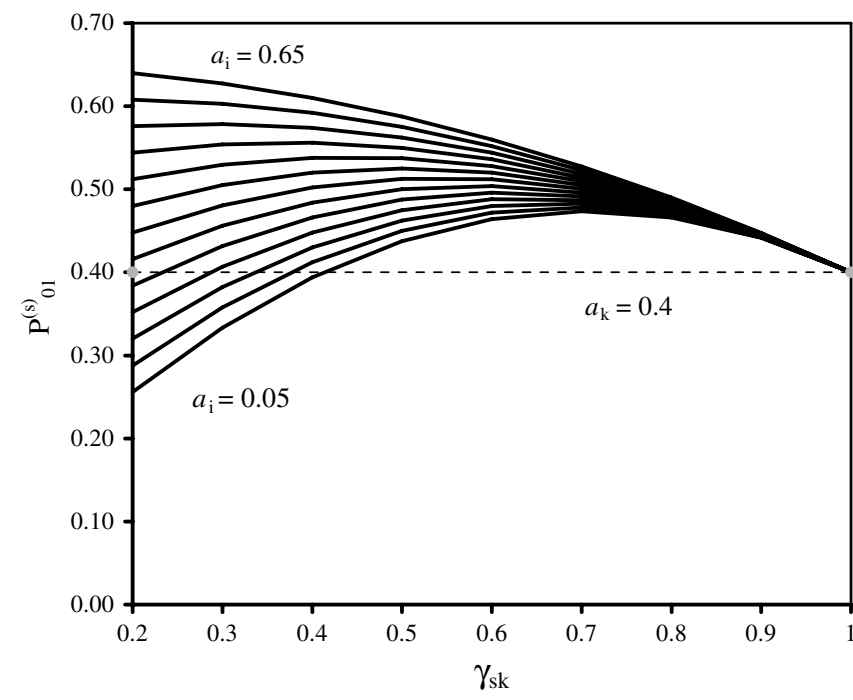

Fig. 1. Transition probability $P_{01}$ of process $X_{s, t}$ from dry to normal years vs. $\gamma_{s k}$ values for transition probability $a_{k}=0.4$ of key site and $\lambda=0.35$. Plots are given for at-site transition probabilities $a_{i}$ from 0.05 to 0.65 .

ing in view of a regional estimation of parameter $\gamma_{s k}$, which may be performed on precipitation records.

Transition probabilities of process $X_{s, t}$ can be derived by applying the axiom of joint probability (see Appendix A1 for details) to the set of values of $X_{k, t}, V_{t}$ and $U_{t}$. Transition probabilities $P_{01}$ (from dry to normal years) and $P_{10}$ (from normal to dry years) are a function of $\lambda$, of the transition probability from dry to normal years of the key site, $a_{k}$, of the at-site transition probability of process $U_{t}, a_{i}$, and of $\gamma_{s k}$.

Parameter $P_{01}$ varies linearly with $a_{i}$ and $a_{k}$ and quadratically with $\gamma_{s k}$ : Fig. 1 shows $P_{01}$ vs. $\gamma_{s k}$ for various $a_{i}$ values and for $a_{k}=0.4$. It can been seen that $P_{01}$ is quite sensitive to the value of $\gamma_{s k}$, i.e. to the correlation of process $X_{s, t}$ with process $X_{k, t}$ at the key site.

\section{Mixture distribution for flow values}

In this model, the marginal distribution of flow values is a direct consequence of the model of drought occurrences. In fact, if the flow process is modelled as an alternation of normal and dry years where $\lambda$ represents the average number of years when a year can be classified as dry, the overall distribution of flows $P$ will be a mixture (or compound) distribution of two populations, one for dry years and one for normal years. Such a distribution is in general bimodal with non zero skewness. If the two subpopulations are assumed to be normal $N\left(\mu_{i}, \sigma_{i}^{2}\right)$ with $i=1,0, P$ is given by

$P\left(\mu, \sigma^{2}\right)=\lambda * N\left(\mu_{1}, \sigma_{1}^{2}\right)+(1-\lambda) * N\left(\mu_{0}, \sigma_{0}^{2}\right)$

First and second-order moment of (3) are provided by Jackson (1975); the third-order moment of the mixture distribution is derived in Appendix A2. Fig. 2 shows the skewness coefficient $\gamma$ for a given $\lambda$ as a function of ratios 


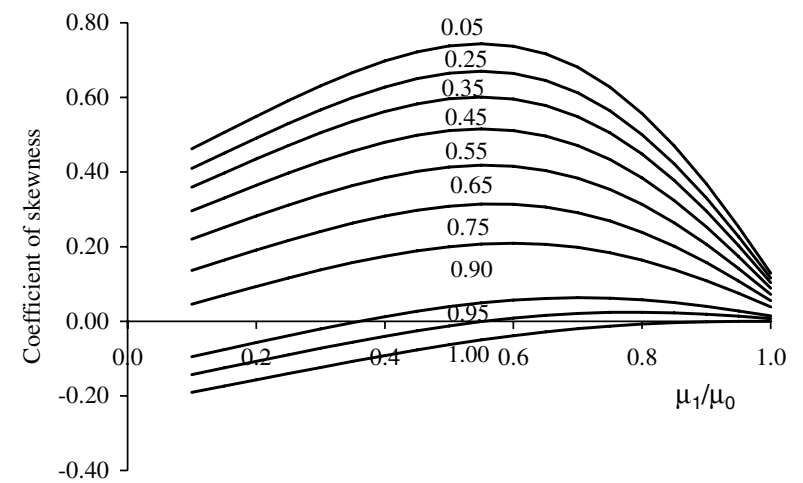

Fig. 2. Skewness coefficient $\gamma$ of a compound distribution vs. $\mu_{1} / \mu_{0}$ for $\sigma_{1} /$ $\sigma_{0}$ ratios from 0.05 to 1 .

$\mu_{1} / \mu_{0}$ and $\sigma_{1} / \sigma_{0}$. It shows that the model is able to generate flows with different $\gamma$.

Two models are selected for reproducing autocorrelation of the historic series (Jackson, 1975): in the first one, the attribution of a flow value to each year is made with no reference to the flow value in the past year or years; in the second one, the following generation scheme is proposed:

$q_{t w}=\mu_{w}+\rho^{\prime} \frac{\sigma_{w}}{\sigma_{i}}\left(q_{t-1, i}-\mu_{i}\right)+\sigma_{w} \varepsilon \sqrt{1-\rho^{\prime 2}}$

Eq. (4) presents the most general situation of a flow $q_{\mathrm{tw}}$ occurring in a year $t$ of type " $w$ " (e.g. dry) to be generated from the flow value occurred in the preceding year which was of type " $i$ "'(normal). Values $\mu_{i}, \mu_{w}, \sigma_{i}$ and $\sigma_{w}$ are mean and standard deviation of flows of type $i$ and $w, \varepsilon$ is a normal standard deviate with zero mean and unit variance and $\rho^{\prime}$ is a coefficient providing further correlation between flows in consecutive years. Fig. 3 shows how the lag-one correlation coefficient $\rho_{1}$ varies with the coefficients of variations of the two normal (for dry and wet years) distributions for four different values of $P_{01}$ (the expression of $\rho_{1}$ may be found in Jackson (1975) for both models). For each value of $P_{01}$, two $\rho_{1}$ vs. $\sigma_{1} / \mu_{1}$ curves are plotted: one with $\rho^{\prime}=0$ and one with $\rho^{\prime}=0.90$ to help visualize the region of variability of $\rho_{1}$ with $\rho^{\prime}$. It should be observed that there are limitations to the values which can be taken on by $\rho_{1}$ for a given transition probability of the series: for instance, with a fraction $\lambda$ of dry flows equal to 0.35 , the greatest admissible value for $\rho^{\prime}=0.99$ will produce in a site with $P_{01}=0.4$ and with $\sigma_{1} / \mu_{1}=\sigma_{0} / \mu_{0}=0.1$, a $\rho_{1}$ not greater than 0.41 . This may result in an under estimation of autocorrelation coefficient in the generated series.

The lag-0 correlation $\rho_{s k}$ between contemporaneous flows at sites $s$ and $k$ provided by the model is derived in Appendix A3 for the case in which $k$ is the key site for $s$. The value of $\rho_{s k}$ turns out to be a function of $\lambda$, of the distribution parameters $\mu_{i}^{(s)}, \mu_{i}^{(k)}, \sigma_{i}^{(s)}$ and $\sigma_{i}^{(k)}(i=0,1)$, of $\rho^{\prime}(s)$ and $\rho^{\prime}(k)$ and of $\gamma_{s k}$. Extensions to other cases in which both $s$ and $r$ are sites with the same key site or $s$ and $r$ are sites with different key sites are also possible.

\section{Parameter estimation}

For the generation of flows at $n$ sites there are $7 n$ parameters to be estimated, namely the value of $\lambda$ (one for all sites), i.e. the fraction of flows to be considered dry, the four parameters of the two normal distributions $\mu_{1}, \mu_{0}$, $\sigma_{1}^{2}, \sigma_{0}^{2}$, the transition probability $a_{i}$, the value of $\rho^{\prime}$ and for all sites but the key site, the value of $\gamma_{s k}$.

Techniques for the contemporaneous estimation of parameters $\mu_{1}, \mu_{0}, \sigma_{1}, \sigma_{0}$ and $\lambda$ of a mixture distribution are reported by Jackson (1975). The Gibbs sampler is used in a Bayesian framework by Thyer and Kuczera (2000) to provide simultaneous estimation of the model parameters in the single-site case and in the multiple site case (Thyer and Kuczera, 2003b) for a hidden-state Markov process. However, all of these methods require a sample size which can be very seldom found in real-world applications as far as contemporaneous series of river flows and spring yields are concerned. In addition, the actual purpose of the paper

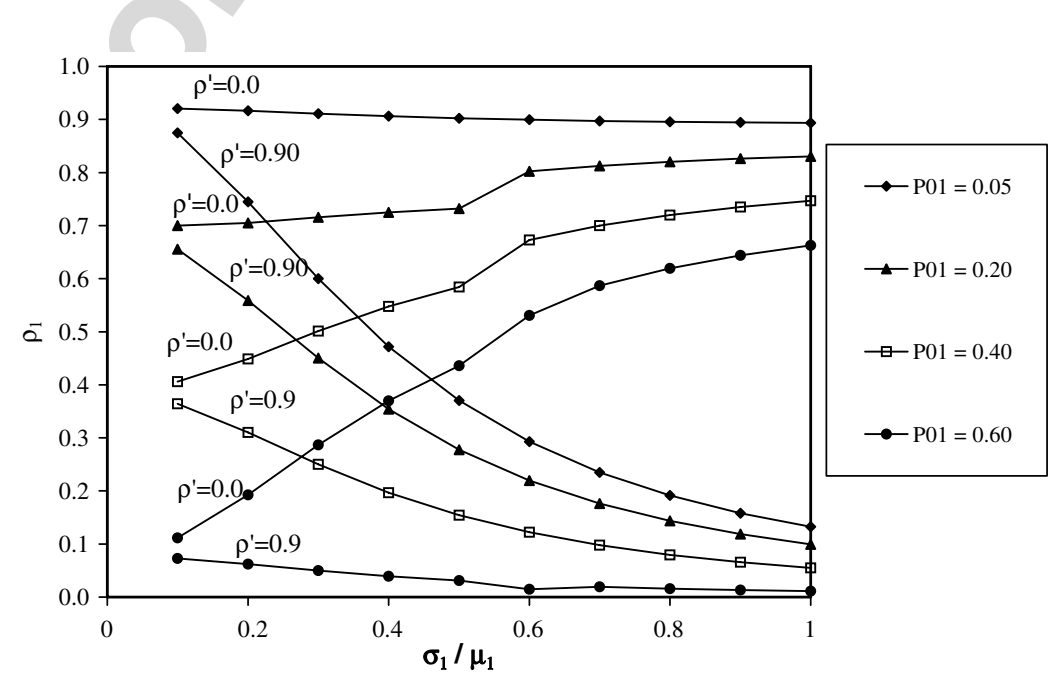

Fig. 3. Lag-1 correlation coefficient $\rho_{1}$ vs. $\sigma_{1} / \mu_{1}$ ratio for different $P_{01}$ values (for each $P_{01}$ value, $\rho_{1}$ is plotted for $\rho^{\prime}=0$ and $\rho^{\prime}=0.90$ ). $\lambda=0.35$. 


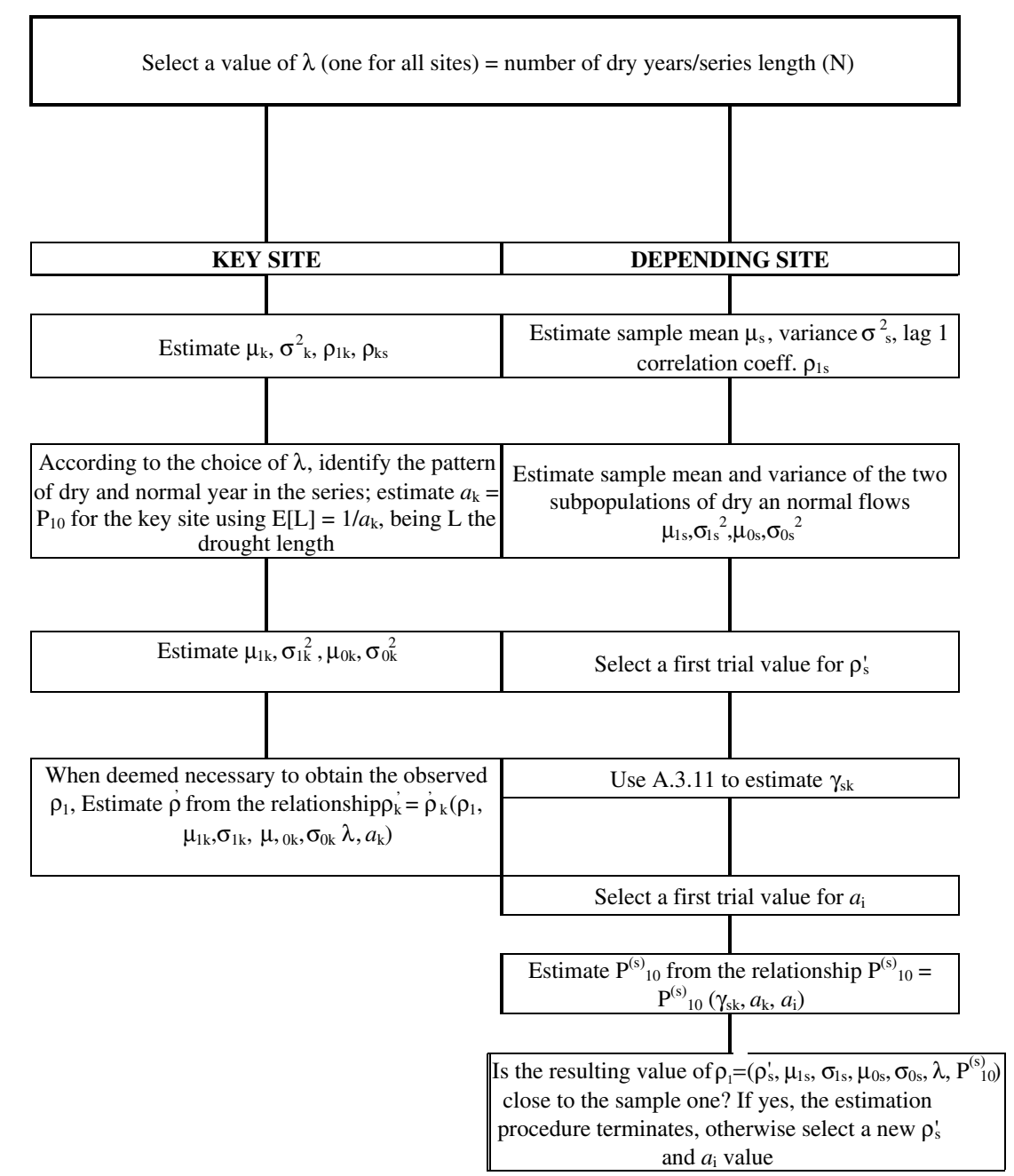

Fig. 4. Parameter estimation procedure of a multisite Markov mixture model for the key site and the depending sites.

is to introduce and evaluate a model for drought frequency analysis; hence, for exploratory purposes, we may resort to simpler methods of estimation, but a comparison between these results and those that could be obtained by more rigorous estimation procedures is in order.

One can therefore explore the parameter space by fixing $\lambda$, the percentage of flows which must be considered as belonging to the population of low flows, and deriving the other parameters as follows: estimates of $\mu_{1}, \mu_{0}, \sigma_{1}$, $\sigma_{0}$ are obtained as the sample mean and standard deviation of the two sub-populations; estimates of $a_{k}$, the transition probability at the key site, may be obtained from the historic record of normal and dry years through the relationships linking mean and variance of drought length to $a_{k}$, (Jackson, 1975); as for the estimation of $a_{i}$, physical considerations should lead to the selection of its appropriate value, ranging from low values for those supply source with long-term persistence (e.g. springs) to higher values, close to independence, for supply sources such as ephemeral streams. The investigation of this issue is in order: the provisionally adopted criterion is to select the $a_{i}$ value which yields a value of the transition probability $P_{10}^{(s)}$ that allows an adequate reproduction of the lag-1 correlation coefficient of the series with a $\rho^{\prime}$ ranging from 0 to 1 . The values of $\gamma_{s k}$ may be obtained from the expression of the lag- 0 coefficient between site $s$ and its key site $k$ in such a way that the lag- 0 correlation between one site and its key site is preserved. Fig. 4 illustrates the estimation procedure.

\section{Model verification}

Testing of a streamflow generation technique is usually performed by controlling that some statistics of the historic record are preserved by the model. Such statistics are usually the first three moments of the marginal distribution of flows and the autocorrelation function of the flow process. When applying a model for drought frequency analysis, however, it is advisable to perform specific validation on some drought-related statistics that can be extracted from the series (Salas, 1993). A well established procedure (e.g. Frick et al., 1990) is to generate a large number of simulated series, say 150, of the same length as the historic record and to identify in each of such series the longest 
drought duration $D_{\max }$ and the greatest cumulate deficit $S_{\max }$. Averages of $D_{\max }$ and $S_{\max }$ over the 150 series are then compared with the historic drought statistics. In this section, both drought duration and severity are assessed with reference to the long term mean. Another useful statistics is the greatest drought intensity $I_{\max }(I$ equals drought severity divided by its duration).

The two longest historic records available in Sicily have been used for model verification: one is the entire series (1928-1980) of yearly flows of San Leonardo river at Monumentale, the other is the 74 years. long series of flows of Oreto river at Parco. Table 1 contains a comparison of historic and generated basic statistics and Table 1a contains a comparison of historic and generated drought statistics (average values over 150 series). Three different values of $\lambda(0.20 ; 0.35$ and 0.50$)$ were used for model calibration, as the model appears to be quite sensitive to the choice of this parameter, as will be illustrated in the following section. Oreto at Parco was used as key site and flows at both sites were generated according to the guidelines of the preceding section. The model appears to reproduce first and secondorder moment of the marginal distribution of flows quite satisfactorily as well as the lag-1 autocorrelation coefficient $\rho_{1}$, with slight overestimations of $\rho_{1}$ for S. Leonardo at Monumentale (the "depending" site) as $\lambda$ decreases. Skewness is reproduced far less accurately, as it was expected as it is not used in any step of the estimation procedure. Also the lag- 0 coefficient of flows seems to be well reproduced by the model, with increasing overestimations as $\lambda$ decreases. As far as the drought-related statistics are concerned, the model provides series with longer average and maximum drought durations than the observed ones for Oreto a Parco and longer average, but shorter maximum durations for $\mathrm{S}$. Leonardo a Monumentale. Drought severity (both average and maximum) is slightly overestimated for Oreto at Parco while maximum drought severity for S. Leonardo at Monumentale is underestimated, especially for bigger $\lambda$ values, while average values are well reproduced. Both average and maximum drought intensity supplied by the model appear to be consistent with the observed ones for both test records. There exists some kind of sensitivity of the drought statistics to $\lambda$, especially for San Leonardo a Monumentale, where decreasing $\lambda s$ provide values of maximum drought severity closer to the observed one. However, based on these results, it seems that all $\lambda$ values feature advantages and disadvantages from the standpoint of the reproduction of the observed drought statistics, so that it hardly makes sense to select a "best" or optimal $\lambda$ value if some kind of likelihood function is not defined. This issue is clearly closely related to that of parameter estimation and will be the object of a future work.

Tables $1 \mathrm{a}$ and $1 \mathrm{~b}$ also report basic and drought statistics for a bivariate ARMA model of yearly flows of Oreto a Parco and San Leonardo a Monumentale. A similar model will be used in Section 9 to perform a comparison with the novel multisite Markov mixture model on their performances in drought simulation. Details on the identification

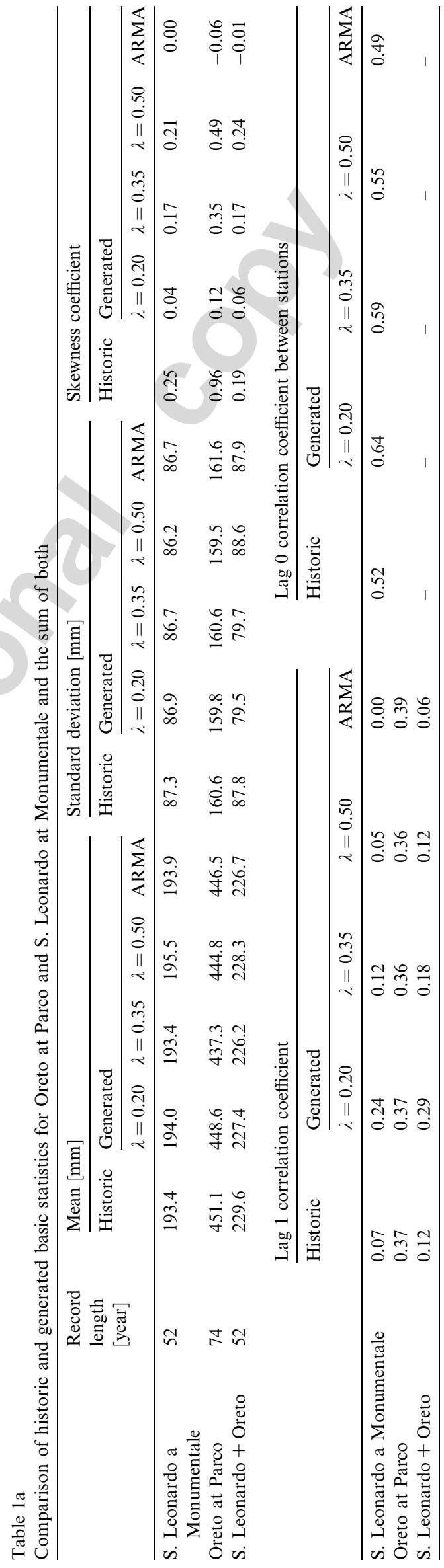




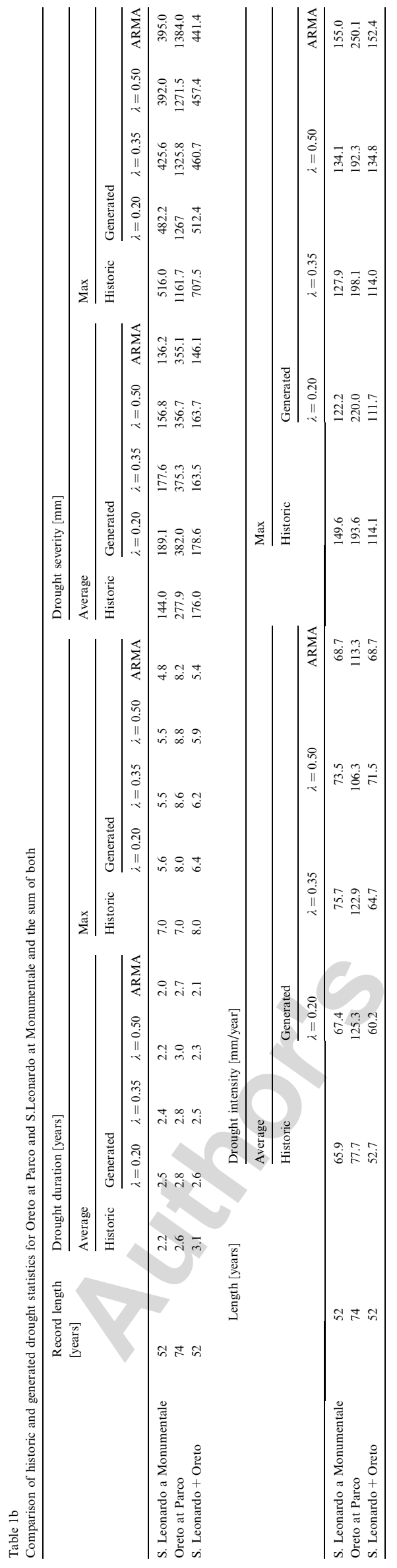

and estimation procedure are provided in Section 8. Model identification led to assume that S.Leonardo river at Monumentale follows an $\operatorname{ARMA}(0,0)$ (a white noise) process and Oreto a Parco can be modeled as an AR(1). First and second-order moment of marginal distributions as well as cross correlation between flows at the two sites are reproduced quite well by the model; as no transformation is applied to reproduced asymmetry, the generated thirdorder moment is null for both series. This seems, however to have little impact on the drought statistics, that are quite close to the historic ones with the exception of an underestimation of maximum drought duration and severity for S. Leonardo a Monumentale and a slight overestimation of the same statistics for Oreto a Parco. Overall, such behaviour is very similar to the one observed for the multisite Markov mixture model.

\section{Model application}

The model has been applied to analyse multiyear drought occurrences in the water resources system supplying Palermo and its environs (Fig. 5). This system is presently constituted by three reservoirs, four spring-groups, three major well-fields and a number of small intakes from rivers. This water system supplies around one million inhabitants of the crowded north-western coast of Sicily as well as irrigation districts and industrial areas. This area has experienced a five-year drought which commenced in water year 1988/1989 and lasted at least until water year 1992/1993, although some supply sources did not recover from drought until water year 1995/1996. A detailed description of this drought event is reported in Mazzola et al. (1999). Drought severity had a peak in 1989/1990 when the reduction of water yield was about $60 \%$ of the long term mean.

In this paper, the supply sources considered for risk assessment are the three reservoirs of Scanzano, Piana degli Albanesi and Poma and the three spring groups of Scillato, Gabriele and Risalaimi. For all of the sources considered historic records of different length and quality are available: the Palermo water company (AMAP) supplied water yield data for springs and all the information needed to draw monthly budgets among stored, withdrawn and lost water volumes in reservoirs.

Since the length of the various records in the data set was not homogeneous, it was decided to consider a common period for all supply sources starting in water year $1967 / 1968$ and ending in 1995/1996. The data set also exhibits inconsistencies. For each river basin featuring missing data, inconsistencies were filled by developing simple regression relationships among flow in month $i$, precipitation over the catchment area in month $i$ and flow in the preceding month. Although considerable discrepancies are observed between recorded and reconstructed flows in some month, especially in summers, the predicted monthly means and standard deviations are rather reliable, and so are the aggregated yearly values. 


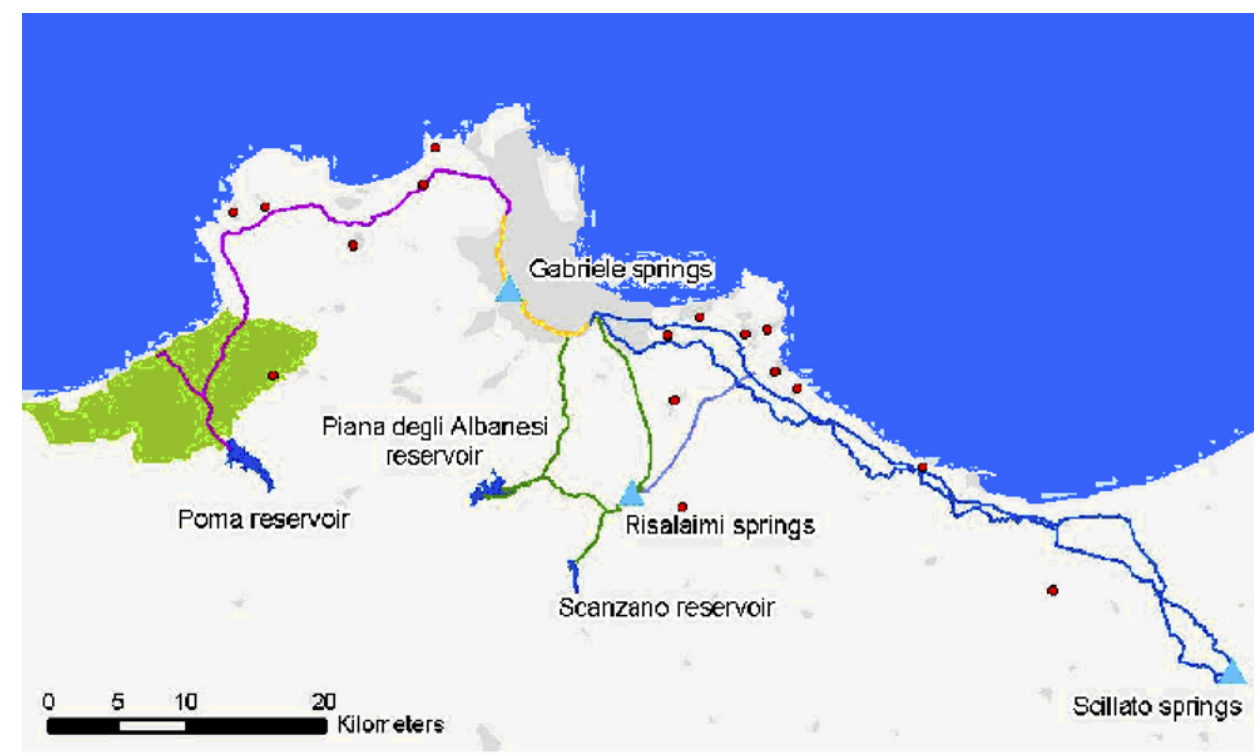

Fig. 5. The Palermo water resources system. Red circles indicate civil demand centers. The green area west is the irrigation area supplied by Poma reservoir. The large gray area is the Palermo urban area. (For interpretation of the references in colour in this figure legend, the reader is referred to the web version of this article.)

Parameter estimation was performed according to the guidelines of the previous section: parameters are reported in Table 2 for a choice of $\lambda=0.35$. Given its central position in the area under study, Scanzano reservoir was selected as key site for three other sites: Piana reservoir, Scillato and Risalaimi springs. Poma reservoir has Piana reservoir as a key site (see Fig. 5). Gabriele spring does not show any significant correlation with the other sites and is hence modelled independently. The effect of path selection on model performance was not investigated. A series of 20,000 yearly flows was generated for each site for three different values $(0.20,0.35$ and 0.50$)$ of $\lambda$, the frac- tion of flows over the series' length to be considered low: Table 3 shows a comparison between historic and generated mean, standard deviation, coefficient of skewness and first serial correlation coefficient $\rho_{1}$, for $\lambda=0.35$.

\section{Multisite ARMA model for yearly flow generation}

In order to compare the results supplied by the multisite Markov mixture model (M.m.m. in the following) and contrast its performances, a multivariate ARMA model has been fitted to the series. The modelling approach suggested by Salas et al. (1980) and Loucks et al. (1981) is followed

Table 2

Estimated parameters of the multisite M.m.m. for the selected sites $-\lambda=0.35$

\begin{tabular}{|c|c|c|c|c|c|c|c|}
\hline Sites & & $\mu_{1}\left[10^{6} \mathrm{~m}^{3}\right]$ & $\sigma_{1}\left[10^{6} \mathrm{~m}^{3}\right]$ & $\mu_{2}\left[10^{6} \mathrm{~m}^{3}\right]$ & $\sigma_{2}\left[10^{6} \mathrm{~m}^{3}\right]$ & $a_{i}$ & $\rho^{\prime}$ \\
\hline \multirow{3}{*}{ Reservoirs } & Scanzano & 8.06 & 4.16 & 21.17 & 6.09 & 0.30 & 0.40 \\
\hline & Piana degli Albanesi & 8.42 & 3.03 & 17.08 & 1.99 & 0.40 & 0.20 \\
\hline & Poma & 24.69 & 8.23 & 53.57 & 10.00 & 0.30 & 0.00 \\
\hline \multirow[t]{3}{*}{ Springs } & Scillato & 16.34 & 2.37 & 21.71 & 1.31 & 0.05 & 0.99 \\
\hline & Risalaimi & 5.86 & 1.09 & 8.91 & 1.16 & 0.05 & 0.40 \\
\hline & Gabriele & 4.93 & 0.31 & 5.71 & 0.33 & 0.05 & 0.30 \\
\hline
\end{tabular}

Table 3

Comparison of historic $(\mathrm{h})$ and generated $(\mathrm{g})($ Multisite Markov mixture model $-\lambda=0.35$ ) basic statistics for the sites considered

\begin{tabular}{|c|c|c|c|c|c|c|c|c|c|}
\hline \multirow[t]{2}{*}{ Sites } & \multirow[t]{2}{*}{$\nabla$} & \multicolumn{2}{|c|}{$\mu\left[10^{6} \mathrm{~m}^{3}\right]$} & \multicolumn{2}{|c|}{$\sigma\left[10^{6} \mathrm{~m}^{3}\right]$} & \multicolumn{2}{|l|}{$\gamma$} & \multicolumn{2}{|l|}{$\rho_{1}$} \\
\hline & & $\mathrm{h}$ & $\mathrm{g}$ & $\mathrm{h}$ & g & $\mathrm{h}$ & $\mathrm{g}$ & $\mathrm{h}$ & $\mathrm{g}$ \\
\hline \multirow[t]{3}{*}{ Reservoirs } & Scanzano & 16.80 & 16.98 & 8.31 & 8.39 & 0.10 & -0.01 & 0.55 & 0.56 \\
\hline & Piana degli Albanesi & 14.19 & 14.30 & 4.76 & 4.74 & -0.79 & -0.79 & 0.29 & 0.30 \\
\hline & Poma & 42.98 & 43.34 & 16.91 & 16.74 & -0.16 & -0.21 & 0.18 & 0.43 \\
\hline \multirow[t]{3}{*}{ Springs } & Scillato & 19.92 & 19.65 & 3.08 & 3.13 & -0.95 & -0.82 & 0.72 & 0.49 \\
\hline & Risalaimi & 7.89 & 7.88 & 1.84 & 1.86 & -0.22 & -0.30 & 0.38 & 0.39 \\
\hline & Gabriele & 5.45 & 5.44 & 0.48 & 0.49 & -0.13 & -0.12 & 0.73 & 0.75 \\
\hline
\end{tabular}


based on the assumption of diagonality for the coefficient matrices $\boldsymbol{\Phi}$ and $\boldsymbol{\Theta}$. This implies, in the general multi-site ARMA( 1,1$)$ model for the generation of $N$ yearly flows at $n$ sites,

$\mathbf{X}_{t}=\boldsymbol{\Phi} \mathbf{X}_{t-1}+\mathbf{V}_{t}-\boldsymbol{\Theta} \mathbf{V}_{t-1}$

the elements of $\boldsymbol{\Phi}$ and $\boldsymbol{\Theta}$ are the parameters of univariate $\operatorname{ARMA}(1,1)$ models fitted at each site. In (5) $\mathbf{X}_{\mathrm{t}}$ is an $n \times 1$ vector of normally distributed flow residuals (zero mean) occurring at the $n$ sites at time $t$ and $\mathbf{V}_{t}$ is an $n \times 1$ vector of normally distributed random fluctuations with covariance matrix G. Spatial correlation among concurrent flows at different sites is provided by the innovations $\mathbf{V}_{t}$ which are independent in time, but correlated in space, through their covariance matrix.

Under the assumption of diagonality for $\boldsymbol{\Phi}$ and $\boldsymbol{\Theta}$, the model fitting process consists of two independent stages: estimation of $\phi_{1 i}$ and $\theta_{1 i}, i=1, \ldots, n$ and estimation of $\mathbf{G}$ conditioned on $\boldsymbol{\Phi}$ and $\boldsymbol{\Theta}$.

As far as the first step is concerned, a mixed approach, based on traditional analysis and on conceptual congruency was followed. Model selection according to traditional analysis is based on the study of the empirical autocorrelogram and on the empirical partial autocorrelogram of the series to which a model is to be fitted (e.g. Salas et al., 1980), whereas the conceptual framework proposed by Claps et al. (1993) restricts the choice of a model for flows at annual scale either to a white noise for ephemeral streams or to an $\operatorname{ARMA}(1,1)$ process for streams with a significant groundwater component. For springs, a third choice, namely an $\mathrm{AR}(1)$ process, is compatible with the conceptual scheme proposed by Claps et al. (1993).

The historic records were tested for normality by Pearson's test, the hypothesis of normality for all of the series could not be rejected at a $5 \%$ significance level, but that of Scillato spring.

Estimation of parameters $\phi$ and $\theta$ was carried out as a first trial by method of moments and the thereby estimated parameters were used as starting point for the search of parameters $\phi$ and $\theta$ minimising the sum of squares of residuals. For each choice of $\phi$ and $\theta$, residuals were obtained by iterative backward procedure (Box and Jenkins, 1976).

An AR(1) model was fitted to the three spring groups after examination of partial autocorrelogram and as a
Table 4

Estimated parameters for the at-site $\operatorname{ARMA}(p, q)$ models

\begin{tabular}{llllllll}
\hline Sites & & $\phi$ & $\sigma(\phi)$ & $\theta$ & $\sigma(\theta)$ & $\sigma^{2}(\epsilon)$ & $R^{2}$ \\
\hline Reservoirs & Scanzano & 0.858 & 0.145 & 0.473 & 0.25 & 0.6498 & 0.35 \\
& Piana degli & 0.750 & 0.259 & 0.436 & 0.350 & 0.7816 & 0.22 \\
& Albanesi & & & & & & \\
& Poma & 0.844 & 0.341 & 0.727 & 0.44 & 0.9244 & 0.08 \\
\multirow{5}{*}{ Springs } & Scillato & 0.732 & 0.149 & - & 0.219 & 0.4642 & 0.54 \\
& Risalaimi & 0.578 & 0.226 & - & 0.277 & 0.389 & 0.61 \\
& Gabriele & 0.882 & 0.086 & - & 0.182 & 0.0395 & 0.96 \\
\hline
\end{tabular}

result of Least Square (LS) estimation of parameters which provided values of $\theta$ of around $10^{-2}$.

Selection of a model for the remaining sites was a more controversial issue: physical grounds suggest that persistence should not be strong for these rivers which are characterised by a reduced groundwater contribution; on the other hand, data analysis via empirical autocorrelograms and partial autocorrelagrams and parameter estimates seem to indicate the contrary. The reason of such discrepancy is to be sought in the reduced length of the record used for calibration, containing a long dry period; however, ignoring persistence may lead to underestimate historic drought parameters; thus, it was decided to accept the $\operatorname{ARMA}(1,1)$ as a model for yearly flows of these streams. The results of the estimation procedure are reported for all the sources considered in Table 4.

Model calibration for each site $s_{i}$ allowed to obtain residuals $\varepsilon_{i t}$ : it is assumed that residuals can be expressed as $\varepsilon_{i t}=\mathbf{B} \xi_{i t}$

in which $\varepsilon_{i t}$ is a vector $(1 \times s$ sites $)$ of residuals independent in time but spatially correlated, $\mathbf{B}$ is a matrix $(s \times s)$ of coefficients and $\xi_{i t}$ is a vector $(1 \times s$ sites $)$ of normal standard deviates with zero mean and unit variance. Before the estimation of $\mathbf{B}, \varepsilon_{i t} s$ were tested for normality and for lack of correlation of time via the Portmanteau lack-of-fit test.

Estimation of elements of $\mathbf{B}$ was carried out according to Salas et al. (1980), considering that the covariance matrix of residuals $\mathbf{G}$ is the Gramian of matrix $\mathbf{B}$ (Bras and Rodriguez Iturbe, 1993). The covariance matrix of residuals $\mathbf{G}$ was estimated by the method of moments (Stedinger et al., 1985). It should be observed that asymmetry is not well reproduced by the model as a consequence of the assumption of normality of the series; however, no trans-

Table 5

Comparison of basic statistics of historic (h) and generated $(\mathrm{g})$ series by ARMA MOM

\begin{tabular}{|c|c|c|c|c|c|c|c|c|c|}
\hline \multirow[t]{2}{*}{ Sites } & \multirow[t]{2}{*}{$\checkmark$} & \multicolumn{2}{|c|}{$\mu\left[10^{6} \mathrm{~m}^{3}\right]$} & \multicolumn{2}{|c|}{$\sigma\left[10^{6} \mathrm{~m}^{3}\right]$} & \multicolumn{2}{|l|}{$\gamma$} & \multicolumn{2}{|l|}{$\rho_{1}$} \\
\hline & & $\mathrm{h}$ & $\mathrm{g}$ & $\mathrm{h}$ & $\mathrm{g}$ & $\mathrm{h}$ & $\mathrm{g}$ & $\mathrm{h}$ & $\mathrm{g}$ \\
\hline \multirow[t]{3}{*}{ Reservoirs } & Scanzano & 16.80 & 16.70 & 8.31 & 7.74 & 0.10 & 0.16 & 0.55 & 0.51 \\
\hline & Piana degli Albanesi & 14.19 & 14.11 & 4.76 & 4.56 & -0.79 & 0.03 & 0.29 & 0.26 \\
\hline & Poma & 42.98 & 43.35 & 16.91 & 16.37 & -0.16 & 0.20 & 0.18 & 0.14 \\
\hline \multirow[t]{3}{*}{ Springs } & Scillato & 19.92 & 19.88 & 3.08 & 3.04 & -0.95 & -0.05 & 0.72 & 0.73 \\
\hline & Risalaimi & 7.89 & 7.86 & 1.84 & 1.87 & -0.22 & 0.00 & 0.38 & 0.40 \\
\hline & Gabriele & 5.45 & 5.46 & 0.48 & 0.51 & -0.13 & 0.01 & 0.73 & 0.74 \\
\hline
\end{tabular}


formation was applied either to the data or to residuals to reproduce asymmetry (Table 5).

\section{Data analysis for drought frequency assessment}

The data generated for each site at year $i$ are summed to give the overall water yield of the whole system in year $i$. 20,000 years have been generated for each site. The analysis of the yearly overall water yield was performed using the procedure described by Frevert et al. (1989), i.e. by first dividing the 20,000 years series in 20 sub-series of 1000 years. In each of such 1000 years series, $1000-n+1$ sequences of $n$ years $(n=1,2, \ldots, 8)$ are considered by shifting each time the starting point of one year. The overall water yield in each sequence of $n$ years is compared to a volume varying from $1800 \mathrm{Mm}^{3}$ to $5 \mathrm{Mm}^{3}$ i.e. in a range from circa 0.2 to 15 times the mean annual yield of all supply sources. The number of times in which the overall water yield in a $n$-years sequence is smaller than the given threshold is divided by the number of $n$-years sequences contained in the twenty 1000 years series to give the non-exceedance probability of a given water yield in $n$ years. Results are visualised in Figs. 6a and 6b. The graphs in Fig. 6 can be used to assess the return period of various historical droughts: in water year 1989-1990, for instance, historical data indicate that the overall water yield was $44.3 \mathrm{Mm}^{3}$ corresponding on the curve $n=1$ year, to a non-exceedance probability ranging from 0.013 for the Markov mixture model with $\lambda=0.20$ and 0.0033 for the ARMA. Such probabilities are equivalent to a return period of respectively 77 years and 303 years. Similarly, in water years $1988 / 1989$ and $1989 / 1990$ the overall water yield was of 105.8 $\mathrm{Mm}^{3}$, corresponding, for $n=2$ years, to a return per- iod ranging from 273 years for M.m.m with $\lambda=0.20$ 688 years for M.m.m with $\lambda=0.35$ and ARMA gives 344 years. However, although some source displays flow values higher than the average also in $1991 / 1992$ or $1993 / 1994$, drought did not terminate until the very wet water year 1995/ 1996, during which all reservoirs refilled completely. Therefore, one is interested in assessing the return period of the overall volume made available by the sources during the seven water years from 1988/1989 to $1994 / 1995$ that can be regarded as a single drought phenomenon: for $n=7$ and an overall water yield of $522 \mathrm{Mm}^{3}$, one reads in Fig. $6 \mathrm{~b}$ non-exceedance probabilities ranging from 0.0046 for the M.m.m. with $\lambda=0.35$ and 0.010 for the multisite ARMA, corresponding to a return period of 217 and 98 years, respectively. The M.m.m with $\lambda=0.20$ has an identical value to ARMA i.e. an estimated return period equal to 97 years.

This comparison shows that the two models can lead to quite different results, with return periods generated by the multisite M.m.m showing a considerable sensitivity to the value of parameter $\lambda$, although ARMA and M.m.m $\lambda=0.20$ supply similar results, with M.m.m $\lambda=0.20$ providing lower return periods for almost all of the critical sequences.

These results have been obtained using the series of the aggregated values of flows. Some of the questions arising from these results include: (1) are the models able to reproduce spatial correlation? They may actually give place to marginal (at-site) series with a good reproduction of historic droughts frequency and severity, but may produce overall water availabilities not consistent with the historic pattern of dry periods; (2) are the models capable to reproduce marginal droughts per se at all? (3) is it possible to

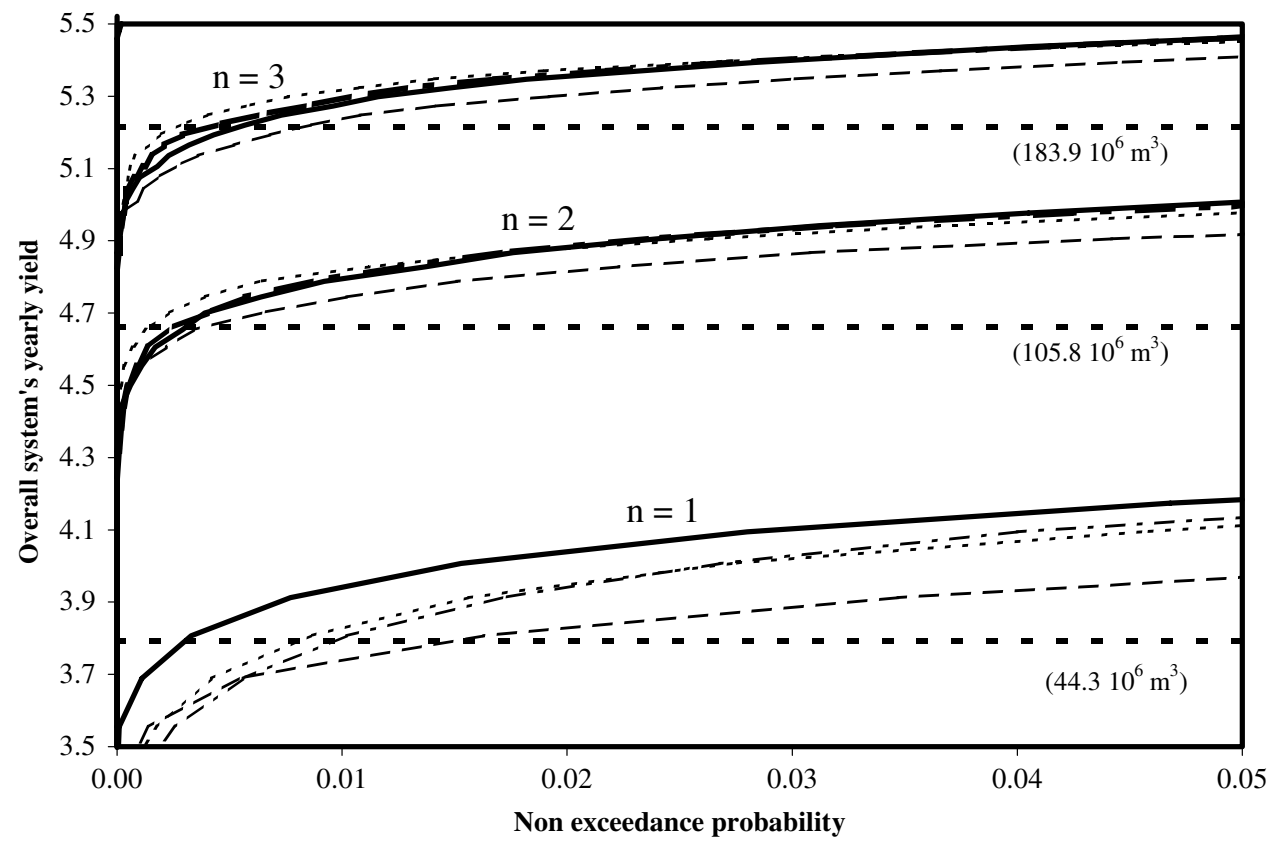

Fig. 6a. Non-exceedance probabilities of given system's overall water yields (logarithmic plot) in $n$ (1, 2 and 3 ) years according to multivariate ARMA (solid line), multisite Markov mixture model with $\lambda=0.20$ (dashed), multisite Markov mixture model with $\lambda=0.35$ (dotted) and with $\lambda=0.50$ (dashdotted line). Horizontal dotted lines are critical historical sequences of 1,2 and 3 years (cumulated flow values are reported in brackets). 


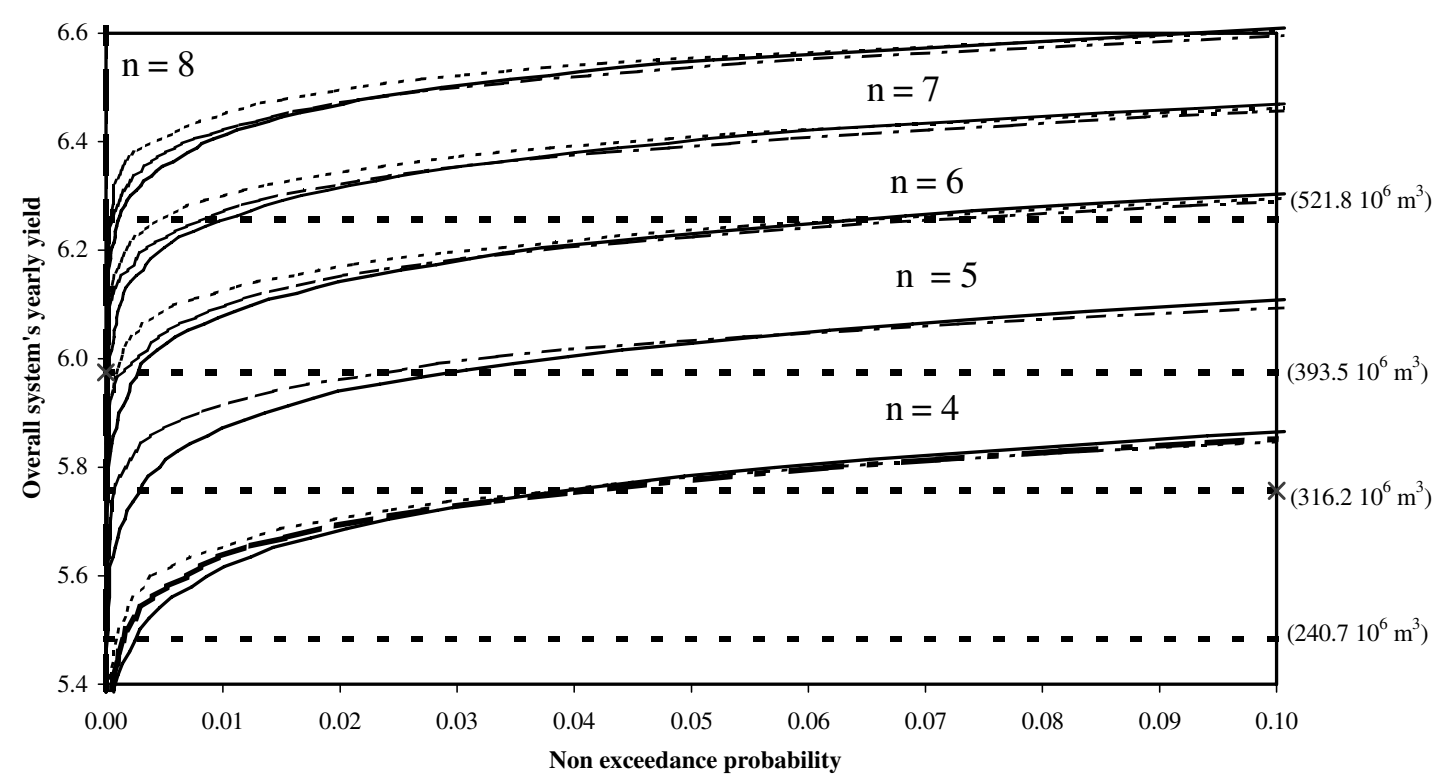

Fig. 6b. Non-exceedance probabilities of given system's overall water yields (logarithmic plot) in $n$ (4 ..,8) years according to multivariate ARMA (solid line), multisite Markov mixture model with $\lambda=0.20$ (dashed), multisite Markov mixture model with $\lambda=0.35$ (dotted) and with $\lambda=0.50$ (dash-dotted line). Horizontal dotted lines are critical historical sequences of 4, 5, 6 and 7 years (cumulated flow values are reported in brackets).

identify some optimal $\lambda$ value for the multisite M.m.m from the standpoint of drought simulation? In order to investigate these issues, the return period of critical sequences of different length was assessed for each site and for the combination of sites for different values of $\lambda(0.20,0.35$ and 0.50 ), as illustrated in Tables $6 \mathrm{a}$ and $6 \mathrm{~b}$. Before discussing the results of Tables $6 a$ and $6 b$, Fig. 7 can also be helpful to understand the different responses provided by the models. It represents the lower tails of the generated cumulative distribution functions (cdf) of yearly flows of Oreto a Parco, San Leonardo a Monumentale and the sum of flows of both sites together with the empirical cdfs estimated by nonparametrical kernel methods (Silverman, 1986). The reason of choosing these two sites clearly resides in the interest for the behaviour of long series and in the availability, for these two sites, of the drought statistics introduced in Section 6. Fig. 7 also contains a table where the return period of historical critical periods lasting $n$ years is shown in an identical fashion as in Tables $6 a$ and $6 \mathrm{~b}$. From the plots it is clear that at least for $\lambda=0.20$ and $\lambda=0.35$, the multisite M.m.m is able to reproduce closely the empirical cdf of flows for Oreto at Parco, whereas the ARMA model seems to fit better than the M.m.m the empirical distribution of San Leonardo and of Oreto $+\mathrm{S}$. Leonardo. The goodness of fit of such lower parts of the cdfs to the empirical one has consequences on both the estimated return periods and, to some degree, on the drought statistics. For S. Leonardo river, the cdfs of the multisite M.m.m. with $\lambda=0.35$ and $\lambda=0.50$ are completely dominated by the historic one which may explain the underestimation of maximum drought severity and the very high estimated return period for $n=7$ years. On the other hand, M.m.m. with $\lambda=0.50$ and ARMA provide almost identical maximum drought severities and very different return peri- ods for the 7 years critical period; this could be due to a different way of generating the severest critical periods for the two models: ARMA generates averagely shorter but more intense critical periods, whereas multiyear droughts generated by the M.m.m are averagely longer and less intense. The cdf provided by the ARMA model crosses the historical one at smaller values than M.m.m. with $\lambda=0.20$ and this explains why the ARMA and the M.m.m. with $\lambda=0.20$ provide smaller return periods respectively for smaller and larger $n$ values. Similar considerations also hold for the sum of flows of Oreto and S. Leonardo. Return periods for lower $n s$ are better estimated by the ARMA model; however, as the pdf of the ARMA model tends to diverge from the historical empirical one for relatively low values of flow, estimations provided by the other models tend to be more reliable for higher $n$ values, with M.m.m. $\lambda=0.20$ supplying very similar values to those generated by ARMA for $n=7$.

Back to the application with six sites, as lower return periods are generated by more conservative models, results of Tables $6 \mathrm{a}$ and $6 \mathrm{~b}$ confirm that only in some cases is the novel multisite M.m.m. able to provide drought frequencies that are more conservative than its ARMA counterparts both at-site and overall. Firstly, it should be observed that, for most site combinations and for all of the selected $\lambda s$, the M.m.m. is able to provide single-year droughts as severe or more severe than the historical one more frequently than the ARMA model; this is still clearer in Table $6 \mathrm{~b}$ where no return period for $n=1$ generated by the multisite M.m.m. is higher than those generated by the ARMA model. Although the above examples show that this fact does not necessarily imply that the marginal distribution of flow is better reproduced by the M.m.m. than by the ARMA model, this provides some further evidence of 
Table 6a

Estimated return period (in years) of historical critical sequences lasting $n$ years (from 1 to 7 ) according to multisite M.m.m. and multivariate ARMA for each source

\begin{tabular}{|c|c|c|c|c|c|c|c|c|c|c|c|c|c|c|c|}
\hline \multirow[t]{4}{*}{ Years } & \multicolumn{15}{|l|}{ Reservoirs } \\
\hline & \multicolumn{5}{|l|}{ Scanzano } & \multicolumn{5}{|c|}{ Piana degli Albanesi } & \multicolumn{5}{|l|}{ Poma } \\
\hline & \multirow{2}{*}{$\begin{array}{l}\text { Critical sequence } \\
{\left[10^{6} \mathrm{~m}^{3}\right]}\end{array}$} & \multicolumn{3}{|l|}{$\lambda$} & \multirow[t]{2}{*}{$\overline{\text { ARMA }}$} & \multirow{2}{*}{$\begin{array}{l}\text { Critical sequence } \\
{\left[10^{6} \mathrm{~m}^{3}\right]}\end{array}$} & \multicolumn{3}{|l|}{$\lambda$} & \multirow[t]{2}{*}{$\overline{\text { ARMA }}$} & \multirow{2}{*}{$\begin{array}{l}\text { Critical sequence } \\
{\left[10^{6} \mathrm{~m}^{3}\right]}\end{array}$} & \multicolumn{3}{|l|}{$\lambda$} & \multirow[t]{2}{*}{ ARMA } \\
\hline & & 0.20 & 0.35 & $\overline{0.50}$ & & & $\overline{0.20}$ & 0.35 & $\overline{0.50}$ & & & 0.20 & 0.35 & 0.50 & \\
\hline 1 & 0.6 & 27 & 76 & 108 & 171 & 2.9 & 40 & 53 & 47 & 113 & 11.6 & 60 & 52 & 39 & 65 \\
\hline 2 & 3.0 & 284 & 2111 & 594 & 233 & 7.1 & 633 & 655 & 339 & 422 & 29.7 & 110 & 209 & 71 & 147 \\
\hline 3 & 14.5 & 38 & 121 & 78 & 40 & 17.2 & 85 & 133 & 90 & 98 & 56.1 & 88 & 176 & 73 & 142 \\
\hline 4 & 19.4 & 53 & 284 & 142 & 52 & 22.0 & 339 & 655 & 271 & 253 & 72.8 & 231 & 679 & 147 & 365 \\
\hline 5 & 29.4 & 48 & 165 & 81 & 38 & 28.5 & 463 & 1727 & 396 & 358 & 100.1 & 181 & 731 & 162 & 322 \\
\hline 6 & 41.1 & 39 & 96 & 54 & 29 & 39.7 & 234 & 475 & 151 & 174 & 146.9 & 61 & 122 & 60 & 95 \\
\hline \multirow[t]{5}{*}{7} & 46.8 & 53 & 178 & 78 & 36 & 48.4 & 243 & 463 & 148 & 168 & 174.0 & 76 & 164 & 76 & 119 \\
\hline & \multicolumn{15}{|l|}{ Springs } \\
\hline & \multicolumn{5}{|l|}{ Scillato } & Risalaimi & \multicolumn{4}{|l|}{ 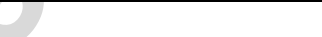 } & \multicolumn{5}{|l|}{ Gabriele } \\
\hline & \multirow{2}{*}{$\begin{array}{l}\text { Critical sequence } \\
{\left[10^{6} \mathrm{~m}^{3}\right]}\end{array}$} & \multicolumn{3}{|c|}{$\lambda$} & \multirow[t]{2}{*}{$\overline{\text { ARMA }}$} & \multirow{2}{*}{$\begin{array}{l}\text { Critical sequence } \\
{\left[10^{6} \mathrm{~m}^{3}\right]}\end{array}$} & \multicolumn{3}{|l|}{$\lambda$} & \multirow[t]{2}{*}{$\overline{\text { ARMA }}$} & \multirow{2}{*}{$\begin{array}{l}\text { Critical sequence } \\
{\left[10^{6} \mathrm{~m}^{3}\right]}\end{array}$} & \multicolumn{3}{|l|}{$\lambda$} & \multirow[t]{2}{*}{ ARMA } \\
\hline & & 0.20 & 0.35 & 0.50 & & & 0.20 & 0.35 & 0.50 & & & 0.20 & 0.35 & 0.50 & \\
\hline 1 & 13.7 & 14 & 19 & 24 & 43 & 3.5 & 90 & 161 & 179 & 100 & 4.6 & 47 & 21 & 34 & 25 \\
\hline 2 & 26.8 & 48 & 41 & 56 & 84 & 8.6 & 88 & 139 & 144 & 82 & 9.2 & 38 & 25 & 37 & 27 \\
\hline 3 & 40.4 & 78 & 54 & 83 & 107 & 14.1 & 78 & 128 & 110 & 85 & 13.9 & 35 & 28 & 39 & 28 \\
\hline 4 & 55.1 & 79 & 57 & 86 & 97 & 19.5 & 114 & 190 & 132 & 119 & 19.0 & 18 & 14 & 20 & 19 \\
\hline 5 & 72.7 & 50 & 35 & 53 & 59 & 25.0 & 137 & 240 & 124 & 161 & 24.4 & 11 & 8 & 10 & 12 \\
\hline 6 & 89.2 & 41 & 30 & 43 & 52 & 32.1 & 76 & 125 & 71 & 103 & 29.7 & 8 & 6 & 7 & 10 \\
\hline 7 & 106.9 & 32 & 24 & 34 & 44 & 38.8 & 60 & 92 & 58 & 88 & 35.1 & 6 & 4 & 5 & 8 \\
\hline
\end{tabular}


Table $6 \mathrm{~b}$

Estimated return period (in years) of historical critical sequences lasting $n$ years (from 1 to 7) according to multisite M.m.m. and multivariate ARMA for different combinations of the supply sources and overall (all sources summed together)

\begin{tabular}{|c|c|c|c|c|c|c|c|c|c|c|}
\hline \multirow[t]{3}{*}{ Years } & \multicolumn{5}{|l|}{ Piana + Scanzano } & \multicolumn{5}{|c|}{ Scillato + Risalaimi } \\
\hline & \multirow{2}{*}{$\begin{array}{l}\text { Critical sequence } \\
{\left[10^{6} \mathrm{~m}^{3}\right]}\end{array}$} & \multicolumn{3}{|l|}{$\lambda$} & \multirow[t]{2}{*}{$\overline{\text { ARMA }}$} & \multirow{2}{*}{$\begin{array}{l}\text { Critical sequence } \\
{\left[10^{6} \mathrm{~m}^{3}\right]}\end{array}$} & \multicolumn{3}{|l|}{$\lambda$} & \multirow[t]{2}{*}{ ARMA } \\
\hline & & 0.20 & 0.35 & 0.50 & & & 0.20 & 0.35 & 0.50 & \\
\hline 1 & 3.5 & 35 & 64 & 77 & 422 & 17.2 & 42 & 104 & 100 & 142 \\
\hline 2 & 10.1 & 905 & 3800 & 422 & 904 & 35.8 & 160 & 213 & 162 & 153 \\
\hline 3 & 31.8 & 56 & 121 & 84 & 76 & 54.7 & 200 & 317 & 250 & 202 \\
\hline 4 & 41.4 & 114 & 487 & 202 & 125 & 74.9 & 263 & 253 & 260 & 218 \\
\hline 5 & 57.9 & 156 & 358 & 165 & 99 & 97.7 & 211 & 162 & 179 & 158 \\
\hline 6 & 80.8 & 80 & 143 & 86 & 61 & 122.4 & 107 & 94 & 106 & 110 \\
\hline \multirow[t]{4}{*}{7} & 95.3 & 111 & 211 & 98 & 69 & 145.7 & 96 & 76 & 86 & 99 \\
\hline & \multicolumn{5}{|c|}{ Piana + Scanzano + Poma } & \multicolumn{5}{|l|}{ Overall } \\
\hline & \multirow{2}{*}{$\begin{array}{l}\text { Critical sequence } \\
{\left[10^{6} \mathrm{~m}^{3}\right]}\end{array}$} & \multicolumn{3}{|l|}{$\lambda$} & \multirow[t]{2}{*}{$\overline{\text { ARMA }}$} & \multirow{2}{*}{$\begin{array}{l}\text { Critical sequence } \\
{\left[10^{6} \mathrm{~m}^{3}\right]}\end{array}$} & \multicolumn{3}{|l|}{$\lambda$} & \multirow[t]{2}{*}{ ARMA } \\
\hline & & 0.20 & 0.35 & 0.50 & & & 0.20 & 0.35 & 0.50 & \\
\hline 1 & 15.1 & 66 & 76 & 72 & 253 & 44.3 & 77 & 116 & 98 & 303 \\
\hline 2 & 39.8 & 633 & 1357 & 311 & 500 & 105.8 & 273 & 698 & 454 & 345 \\
\hline 3 & 87.9 & 121 & 283 & 135 & 178 & 183.9 & 98 & 273 & 252 & 153 \\
\hline 4 & 114.2 & 322 & 1461 & 339 & 404 & 240.7 & 415 & 1083 & 656 & 400 \\
\hline 5 & 158.1 & 333 & 1357 & 380 & 306 & 316.2 & 419 & 1385 & 804 & 348 \\
\hline 6 & 227.7 & 109 & 211 & 107 & 111 & 393.5 & 434 & 1074 & 736 & 365 \\
\hline 7 & 269.3 & 158 & 297 & 135 & 127 & 521.9 & 97 & 217 & 117 & 98 \\
\hline
\end{tabular}
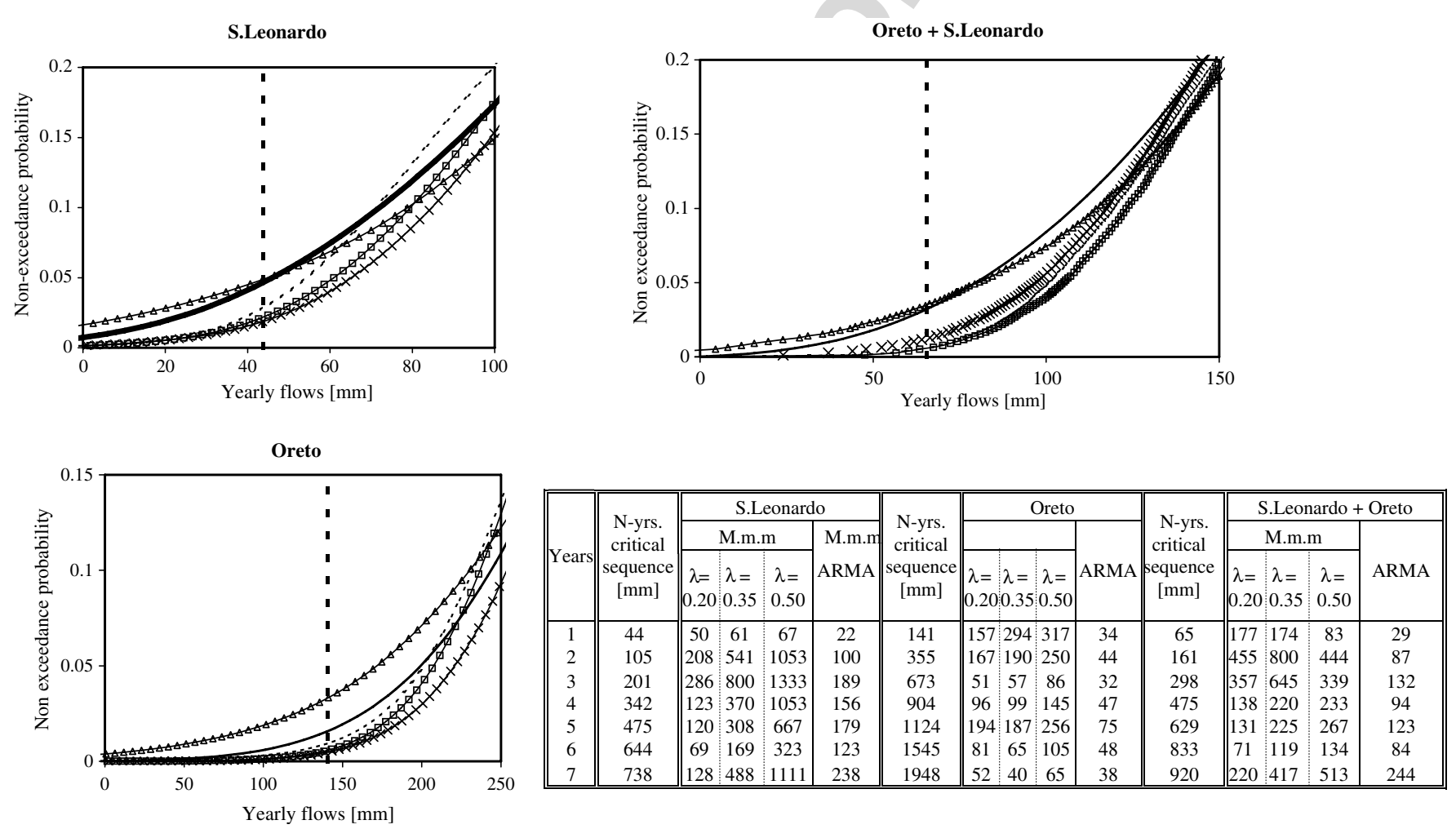

Fig. 7. Lower tails of the observed (solid line) and generated (ARMA-triangles, M.m.m. with $\lambda=0.20$ dotted, M.m.m. with $\lambda=0.35$-squares, M.m.m. with $\lambda=0.50$-crosses) cumulative probability functions of yearly flows of Oreto at Parco, San Leonardo at Monumentale and the sum of both. Dotted vertical lines indicate the 1-years. observed critical period. Table reports the estimated return periods of critical observed sequences of various lengths.

the role played by the shape of the lower tail of the marginal pdf in the assessment of the return period. In any case, when it comes to generating multiyear droughts, the M.m.m. performs less uniformly, both at site and overall. This may seem strange, given that the M.m.m. is designed to produce long sequences of dry years, but the features of the distribution function of the subpopulation of dry flows are probably not able to grant, even in the case of model 2, that a dry year following a very dry year should be very dry as well. This may be the reason why the model seems to 
Site 1 - other sites

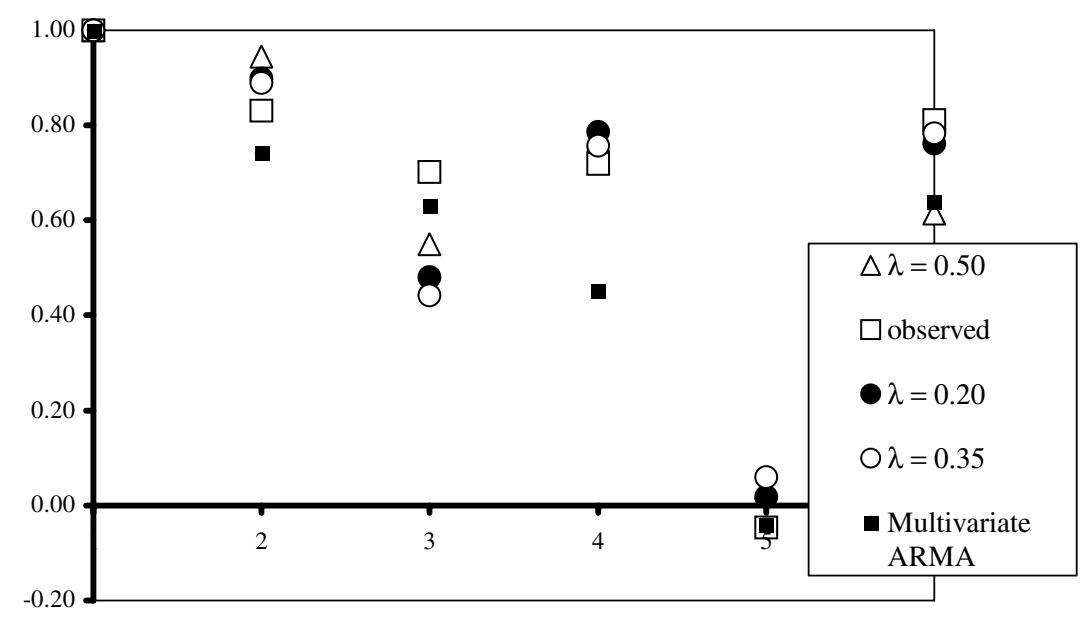

Site 2 - other sites

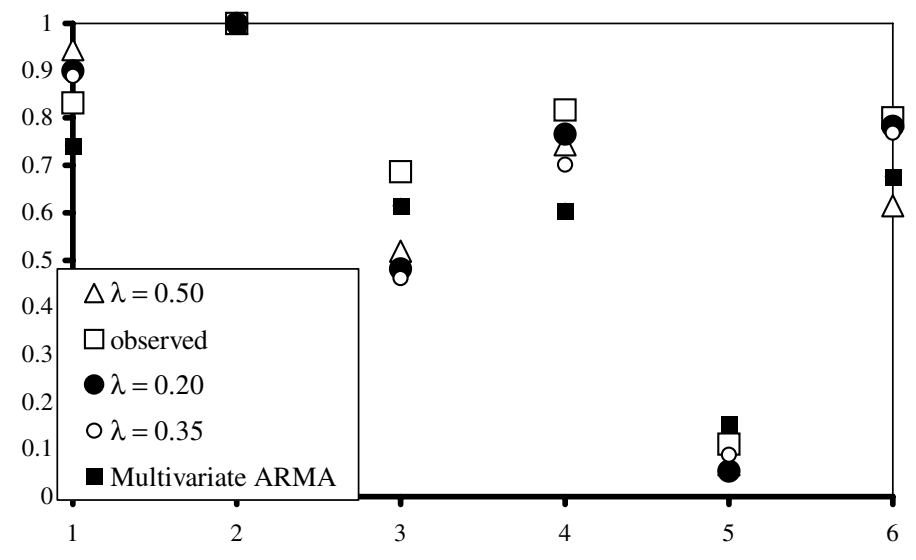

site 3 - other sites

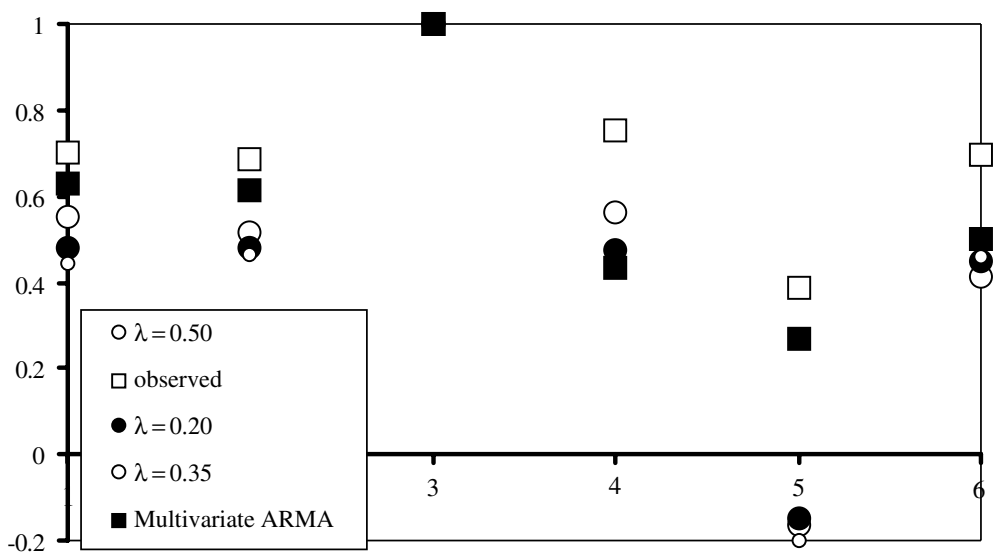

Fig. 8a. Historic and generated lag-0 coefficients between site 1, 2 and 3 and the remaining sites.

supply more conservative results when the selected $\lambda$ is low enough (as in the case of $\lambda=0.20$ ) that yearly flows in dry years are drawn from a distribution with such parameters that the probability that sequences of dry years actually have low flow values is increased.

However, the relationship between $\lambda$ and return period does not appear to be monotonic, as a choice of $\lambda=0.50$ provides results that are in some case only slightly less con- servative than those obtained by selecting $\lambda=0.20$ and in some at-site case even works somewhat better than that with $\lambda=0.20$. This could be due to the fact that the more frequent occurrence of dry years for $\lambda=0.50$ compensates for its higher values of low flows. In any case, results obtained by an intermediate $\lambda$ value $(\lambda=0.35)$ are decidedly less satisfying, pointing out that a search in the parameter space for the optimal parameter set should be 


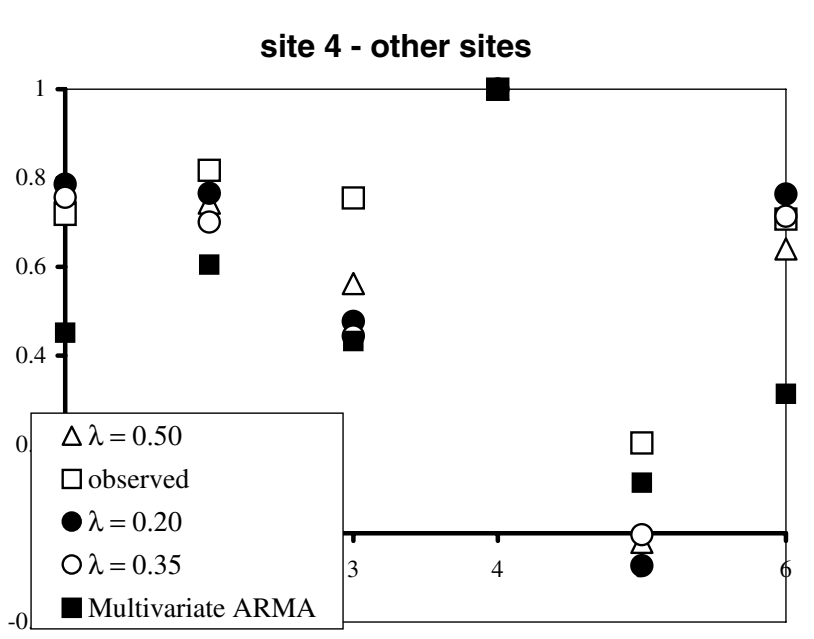

site 5 - other sites
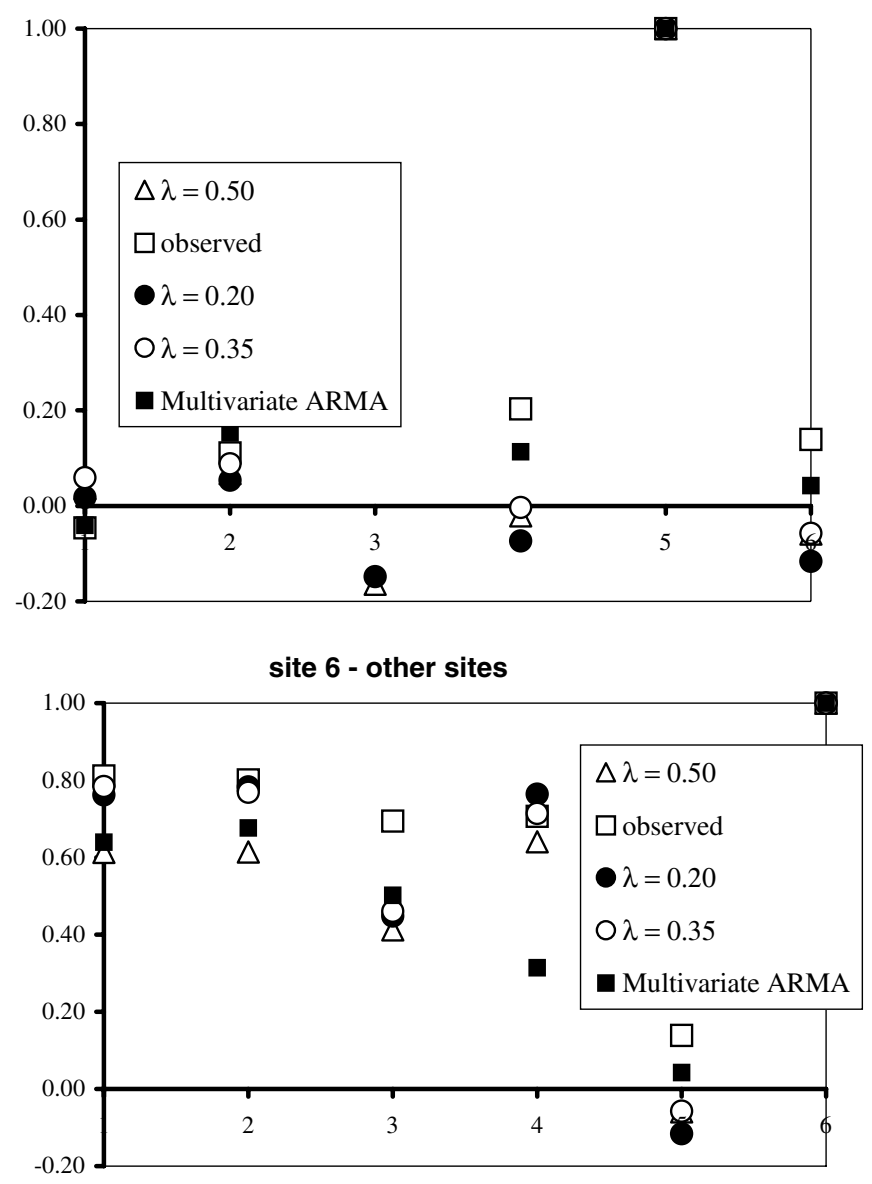

Fig. 8 b. Historic and generated lag- 0 coefficients between site 4,5 and 6 and the remaining sites.

performed in order to ensure good performances of the model. The optimal criteria to be adopted for such a search and the related methods shall be the issue of future research work. However, ultimate evidence of the superiority of a model on the other, if any, could only be obtained by a in vivo test of the models, i.e. by using generated data, possibly disaggregated at the desired time scale, as input to a simulation model of a multi-source water system and com- paring the properties of the generated reliability and vulnerability-related indices.

Secondly, although more objective and formal criteria should be provided to test the multisite M.m.m's ability to reproduce spatial correlation, cross-analysis of Tables $6 \mathrm{a}$ and $6 \mathrm{~b}$ and Fig. 8 where lag-0 correlation coefficients between sites are summarized, does not seem to show that gaining a greater accuracy in the reproduction of spatial correlation would enhance the results of drought frequency analysis, as long as the appropriate $\lambda$ is not selected.

\section{Conclusions}

Two stochastic generation techniques of yearly flows have been compared with regard to the quality of multiyear drought frequency assessments at multiple sites they are able to provide. One of such models, the here introduced multisite Markov mixture model accounts explicitly for the alternation of normal and dry years, whereas the other is the well established multinormal $\operatorname{ARMA}(p, q)$. Such a novel model is motivated by the fact that the evidence that interactions of global climatic mechanisms with quasi-cyclic characteristic produce alternating wet and dry regimes in hydroclimatic time series has been found in a number of regions and this calls for appropriate models. Properties of the newly developed model both at-site and jointly are investigated in terms of transition probabilities, at-site lag-1 correlation coefficients and lag-0 correlation coefficients among sites. In the application to drought frequency assessment of the water resources system supplying Palermo (Italy), parameter estimation is partly given up in favour of a search in the parameter space based on different values of $\lambda$, the number of years over the series length to be considered dry. However, an exhaustive technique for parameter estimation is the major issue of future research efforts. Analysis of results show a sometimes significant variability of the estimated return periods with the model and, within the multisite Markov mixture model, with the value of $\lambda$. However, the mere use of the estimated return period of observed critical sequences of flows of different length as a criterion to infer a superiority of one model on the other appears to be far too reductive, as it seems to be closely related to the shape of the lower parts of the probability distribution of flows which varies from site to site. Lower estimated return periods are not necessarily more realistical than higher ones, as shown with reference to the series employed for model validation. It is remarkable however, that the drought statistics assessed for the two test series of San Leonardo at Monumentale and Oreto at Parco are quite homogeneous for the different models.

Results seem to show that under many conditions and site combinations, the multisite M.m.m. can yield return periods of occurrences of dry periods which are more conservative (i.e. shorter) than those supplied by the multisite ARMA model. In the application, this holds true for most choices of $\lambda$ for one-year droughts, whereas multiyear droughts tend to be assessed more conservatively by either 
low or high values of $\lambda$, with intermediate $\lambda$ values yielding seemingly overestimated return periods of droughts. The proposed space-time model for drought occurrences appears to allow a quite satisfactorily reproduction of spatial correlation among sites, as shown by generated the lag- 0 correlation coefficients. The model introduced hence shows to have a potential to generate yearly flows with the specific aim at reproducing droughts and can be employed in simulation studies of multi-source water systems. In any case, besides the above-mentioned goal of developing an appropriate parameter estimation procedure for the novel multisite Markov mixture model, future research will all focus on the comparison of the impact of such models in simulation studies of a water system with regulated sources.

\section{Appendix A1. Transition probability of the occurrence process of normal and dry years at a site}

Transition probability $P_{i j}^{(s)}$ of flows at site $s$ from state $j$ (dry or normal) at time $t-1$ to state $i$ (normal or dry) at time $t$ is defined as follows:

$P_{i j}^{(s)}=\operatorname{Prob}\left\{X_{s, t}=i \mid X_{s, t-1}=j\right\}$

and may be derived by considering Eq. (2) in the text and the axiom of joint probabilities:

$P_{i j}^{(s)}=\frac{\operatorname{Prob}\left\{X_{s, t}=i ; X_{s, t-1}=j\right\}}{P\left\{X_{s, t-1}=j\right\}}$

$X_{k, t}, V_{t}$ and $U_{t}$ are independent binary processes. Of the $2^{3}=8$ combinations describing all the possible outcomes of terms forming Eq. (4), four yield $X_{s, t}=1$ and the other four yield $X_{s, t}=0$

For instance, at time step $t, X_{s, t}=0$ because

$$
\begin{aligned}
X_{k, t}=1 ; & V_{t}=0 ; & U_{t}=0 \\
X_{k, t}=0 ; & V_{t}=1 ; & U_{t}=1 \\
X_{k, t}=0 ; & V_{t}=1 ; & U_{t}=0 \\
X_{k, t}=0 ; & V_{t}=0 ; & U_{t}=0
\end{aligned}
$$

And at the preceding time step $t-1, X_{s, t-1}=1$ because

$$
\begin{array}{lll}
X_{k, t-1}=1 ; & V_{t-1}=1 ; & U_{t-1}=0 \\
X_{k, t-1}=1 ; & V_{t-1}=1 ; & U_{t-1}=1 \\
X_{k, t-1}=0 ; & V_{t-1}=0 ; & U_{t-1}=1 \\
X_{k, t-1}=1 ; & V_{t-1}=0 ; & U_{t-1}=1
\end{array}
$$

From any of the combinations (A1.2) at time step $t-1$, process $X_{s, t}$ can shift to state 0 at the following time step through any combination (A1.1). If we consider all of the 16 likely combinations, we shall have allowed for all of the possible transitions from state 1 at time $t-1$ to state 0 at time $t$. At a given time step, a combination like (A1.2) excludes all the others and the same holds for combinations of type (A1.1); hence the overall conditional probability that the state at step $t$ is 0 , given that at step $t-1$ it was produced by, say, combination (A1.2a), will be the sum of the transition probabilities from (A1.2a) to each of the combinations (A1.1). Since processes $X_{k, t} ; V_{t}$ and $U_{t}$ are independent, the terms of such sum are the products of the transition probabilities from $X_{k, t-1}$ to $X_{k, t}, V_{t-1}$ to $V_{t}$ and $U_{t-1}$ to $U_{t}$, except for $V_{t}$ which, being a Bernoullian process, has its transition probability from one state to the other simply coinciding with its marginal probability of being in the arrival state. For instance, it can be easily shown that the transition probability from state 1 , as obtained by combination (A1.2a) to state 0 is given by $\left(1-a_{k}\right)\left(1-\gamma_{s k}\right)\left(1-b_{i}\right)+a_{k} \gamma_{s k} b_{i}+a_{k} \gamma_{s k}\left(1-b_{i}\right)$ $+a_{k}\left(1-\gamma_{s k}\right)\left(1-b_{i}\right)$. To obtain the joint probability that any of the combinations (A1.1) occurs at step $t$ and that combination (A1.2a) occurs at step $t-1$, such sums must be multiplied by the marginal probability that combination (A1.2a) occurs which is given by $\lambda(1-\lambda) \gamma_{s k}$, thus yielding:

$$
\begin{aligned}
& {\left[\left(1-a_{k}\right)\left(1-\gamma_{s k}\right)\left(1-b_{i}\right)+a_{k} \gamma_{s k} b_{i}+a_{k} \gamma_{s k}\left(1-\left(b_{i}\right)\right.\right.} \\
& \left.\quad+a_{k}\left(1-\gamma_{s k}\right)\left(1-b_{i}\right)\right] * \lambda(1-\lambda) \gamma_{s k}
\end{aligned}
$$

Since each combination (A1.2) excludes the others at a given time step, the overall joint probability that process $X_{s, t}$ is in state 1 at time $t-1$ and is in state 0 at time $t$ is the sum of four terms like (A1.3). Finally, the transition probability $P_{01}$ is obtained by dividing the overall joint probability by the marginal probability of process $X_{s, t}$ 's being in the departure state.

\section{Appendix A2. Third-order moment of a mixture distribution of two normal subpopulations}

The third order moment measured about the mean is defined as follows:

$$
\begin{aligned}
\lambda_{x}= & \int_{-\infty}^{+\infty}(x-\mu)^{3} f_{X}(x) \mathrm{d} x \\
\lambda_{x}= & \int_{-\infty}^{+\infty} x^{3} f_{X}(x) \mathrm{d} x-\mu^{3} \int_{-\infty}^{+\infty} f_{X}(x) \mathrm{d} x \\
& -3 \mu \int_{-\infty}^{+\infty} x^{2} f_{X}(x) \mathrm{d} x+3 \mu^{2} \int_{-\infty}^{+\infty} x f_{X}(x) \mathrm{d} x \\
\lambda_{x}= & \lambda \int_{-\infty}^{+\infty} x^{3} N\left(\mu_{1}, \sigma_{1}^{2}\right) \mathrm{d} x+(1-\lambda) \int_{-\infty}^{+\infty} x^{3} N\left(\mu_{0}, \sigma_{0}^{2}\right) \mathrm{d} x-\mu^{3} \\
& -3 \mu\left[\lambda \int_{-\infty}^{+\infty} x^{2} N\left(\mu_{1}, \sigma_{1}^{2}\right) \mathrm{d} x+(1-\lambda) \int_{-\infty}^{+\infty} x^{2} N\left(\mu_{0}, \sigma_{0}^{2}\right) \mathrm{d} x\right] \\
& +3 \mu^{2}\left(\lambda \mu_{1}+(1-\lambda) \mu_{0}\right)
\end{aligned}
$$

With $x_{i}=\mu_{i}+\varepsilon \sigma_{i} ; i=0$ (normal), 1 (dry).

Recalling that $E[\varepsilon]=0, E\left[\varepsilon^{2}\right]=1, E\left[\varepsilon^{3}\right]=0$, and rearranging:

$$
\begin{aligned}
\lambda_{X}= & \lambda \mu_{1}^{3}+3 \lambda \mu_{1} \sigma_{1}^{2}+(1-\lambda) \mu_{0}^{3}+3(1-\lambda) \mu_{0} \sigma_{0}^{2}-3 \mu\left[\lambda \mu_{1}^{2}\right. \\
& \left.+\lambda \sigma_{1}^{2}+(1-\lambda) \mu_{0}^{2}+(1-\lambda) \sigma_{0}^{2}\right]+3 \mu_{0}\left[\lambda \mu_{1}+(1-\lambda) \mu_{0}\right]
\end{aligned}
$$

Rearranging one obtains:

$$
\begin{aligned}
\lambda_{X}= & \lambda \mu_{1}^{3}+(1-\lambda) * \mu_{0}^{3}-\mu^{3} \\
& +3 \lambda \sigma_{1}^{2}\left(\mu_{1}-\mu\right)+3(1-\lambda) \sigma_{0}^{2}\left(\mu_{0}-\mu\right) \\
& +3 \lambda\left(\mu^{2} \mu_{1}-\mu \mu_{1}^{2}\right)+3(1-\lambda)\left(\mu_{0} \mu^{2}-\mu \mu_{0}^{2}\right)
\end{aligned}
$$


Appendix A3. Deriving an expression for the lag-0 coefficient between two sites, one being the key site for the other

The lag-0 correlation coefficient between two sites $X^{(s)}$ and $X^{(k)}$ is defined as follows:

$\rho_{s k}=E\left\{\left[X^{(s)}-E\left(X^{(s)}\right)\right] *\left[X^{(k)}-E\left(X^{(k)}\right)\right]\right\} /\left(\sigma_{s} * \sigma_{k}\right)$

that is,

$\rho_{s k}=\frac{E\left[X^{(s)} X^{(k)}\right]-\mu_{s} * \mu_{k}}{\sigma_{s} * \sigma_{k}}$

Model 1 (flow values at a site are drawn from the appropriate subpopulation regardless of the flow value at the same site in the preceding year):

$E\left[X_{i}^{(s)} X_{j}^{(k)}\right]=E\left[\left(\mu_{i}^{(s)}+\varepsilon^{(s)} \sigma_{i}^{(s)}\right) *\left(\mu_{j}^{(k)}+\varepsilon^{(k)} \sigma_{j}^{(k)}\right)\right]$

In the assumption that $\varepsilon^{(s)}=\varepsilon^{(k)}=\varepsilon \forall s, k$, (A3.3) is equal to $\mu_{i}^{(s)} * \mu_{j}^{(k)}+\sigma_{i}^{(s)} * \sigma_{j}^{(k)}$; being $E\left[\varepsilon^{0}\right]=0$ and $E\left[\varepsilon^{2()}\right]=1$ by definition.

Model 2 (flow values at a site are drawn from the appropriate subpopulation taking account of the flow value at the same site in the preceding year according to Eq. (4) in the text):

$$
\begin{aligned}
E\left[X_{i}^{(s)} X_{j}^{(k)}\right]= & E\left[\left(\mu_{i}^{(s)}+\rho^{\prime(s)} \sigma_{i}^{(s)} / \sigma_{j}^{(s)} *\left(q_{j}^{(s)}-\mu_{j}^{(s)}\right)\right.\right. \\
& \left.+\varepsilon^{(s)} \sigma_{i}^{(s)}\left(1-\rho^{\prime(s) 2}\right)^{0,5}\right) * \mu_{j}^{(k)}+\rho^{\prime(k)} \sigma_{j}^{(k)} / \sigma_{i}^{(k)} \\
& \left.*\left(q_{i}^{(k)}-\mu_{i}^{(k)}\right)+\varepsilon^{(k)} \sigma_{j}^{(k)}\left(1-\rho^{\prime(k) 2}\right)^{0,5}\right] \quad(\mathrm{A} 3
\end{aligned}
$$

In these products, terms containing $\left(q^{(0)}-\mu^{(0)}\right) \rightarrow 0$, since $\mathrm{E}\left(q^{(0)}-\mu^{(0)}\right)=E\left(q^{(0)}\right)-\mu^{(0)}=0$; terms containing $\varepsilon^{(s)}$ also go to 0 in the expectation. There remain the following terms:

$\mu_{i}^{(s)} \mu_{j}^{(k)}$;

$\rho^{\prime(s)} \rho^{\prime(k)} \sigma_{i}^{(s)} / \sigma_{j}^{(s)} \sigma_{j}^{(k)} / \sigma_{i}^{(k)} *\left(q_{j}^{(s)}-\mu_{j}^{(s)}\right) *\left(q_{i}^{(k)}-\mu_{i}^{(k)}\right)$

$\varepsilon^{2} \sigma_{j}^{(k)} \sigma_{i}^{(s)}\left(1-\rho^{\prime(s) 2}\right)^{0,5}\left(1-\rho^{\prime(k) 2}\right)^{0,5}$

The expectation of product $X^{(s)} X^{(k)}$ may be written as follows:

$E\left[X^{(s)} X^{(k)}\right]=\sum_{i=0}^{1} \sum_{j=0}^{1} P_{s k}(i, j) * E\left[X_{i}^{(s)} X_{j}^{(k)}\right]-\mu_{s} \mu_{k}$

It is noteworthy that there exists a different expression of $E\left[X_{i}^{(s)} X_{j}^{(k)}\right]$ for each of the four possible combinations of $X_{i}^{(s)}$ and $X_{j}^{(k)}$, depending from the state of sites $s$ and $k$ al time step $t$ and at the preceding one: the appropriate value of the transition probability should hence be applied to each of the likely values. However, this should only be done for terms (A3.6) since terms (A3.5) and (A3.7) are not affected by the state of the preceding time step, but the very same actually holds also for (A3.6): if one develops products in (A3.6), one finds that each of them equals $\rho^{\prime(s)} \rho^{\prime(k)} \sigma_{i}^{(s)} \sigma_{j}^{(k)}$ : leaving aside $\rho^{\prime(s)} \rho^{\prime(k)} \sigma_{i}^{(s)} / \sigma_{j}^{(s)} \sigma_{j}^{(k)} / \sigma_{i}^{(k)}$, the expected value of $\left(q_{j}^{(s)}-\mu_{j}^{(s)}\right) *\left(q_{i}^{(k)}-\mu_{i}^{(k)}\right)$ equals $E\left(q_{j}^{(s)}\right.$ $\left.q_{i}^{(k)}\right)-\mu_{j}^{(s)} \mu_{i}^{(k)}$. Each of such terms equals $\mu_{j}^{(s)} \mu_{i}^{(k)}+$ $\sigma_{j}^{(s)} \sigma_{i}^{(k)}-\mu_{j}^{(s)} \mu_{i}^{(k)}$, i.e. $\sigma_{j}^{(s)} \sigma_{i}^{(k)}$, which yields $\rho^{(s)} \rho^{(k)} \sigma_{i}^{(s)} \sigma_{j}^{(k)}$, when multiplied by $\rho^{(s)} \rho^{\prime(k)} \sigma_{i}^{(s)} / \sigma_{j}^{(s)} \sigma_{j}^{(k)} / \sigma_{i}^{(k)}$ for each of the four possible combinations; hence one has

$$
\begin{aligned}
E\left[X^{(s)} X^{(k)}\right]= & \sum_{i=0}^{1} \sum_{j=0}^{1} P_{s k}(i, j) *\left[\mu_{i}^{(s)} \mu_{j}^{(k)}+\rho^{\prime(s)} \rho^{\prime(k)} \sigma_{i}^{(s)} \sigma_{j}^{(k)}\right. \\
& \left.+\sigma_{j}^{(k)} \sigma_{i}^{(s)}\left(1-\rho^{(s) 2}\right)^{0,5}\left(1-\rho^{\prime(k) 2}\right)^{0,5}\right]-\mu_{s} \mu_{k}
\end{aligned}
$$

where $P_{s k}(i, j)$ is the joint probability that site $s$ is in state $i$ and site $k$ is in state $j . P_{s k}(i, j)$ can be evaluated using the axiom of joint probability:

$P_{s k}(i, j)=\operatorname{Pr}\left\{X_{k}=j\right\} * \operatorname{Pr}\left\{X_{s}=i \mid X_{k}=j\right\}$

Conditional probabilities $\operatorname{Pr}\left\{X_{s}=i \mid X_{k}=j\right\}$ are found recalling the adopted space-time model: (Eq. (2) in the text) $X_{s, t}=V_{s k, t} \cdot \mathrm{X}_{s, t}+\left(1-V_{s k, t}\right) \cdot U_{s, t}$.

Hence

$P_{00}=\operatorname{Pr}\left\{X_{k}=0\right\} * \operatorname{Pr}\left\{X_{s}=0 \mid X_{k}=0\right\}$

$\operatorname{Pr}\left\{X_{k}=0\right\}=1-\lambda$

$X_{s, t}=0 \quad$ when $X_{k, t}=0 \quad$ if :

$V_{s k, t}=1 \quad$ and $\quad U_{s, t}=0$

$V_{s k, t}=1 \quad$ and $\quad U_{s, t}=1$

$V_{s k, t}=0 \quad$ and $\quad U_{s, t}=0$

Events A3.10a,A3.10b and A3.10c are mutually excluding, hence their occurrence probability must be summed.

Each of the events (A3.10) is the composition of two events, $V$ e $U$ which are independent, hence their occurrence probabilities must be multiplied:

$$
\begin{aligned}
& \begin{aligned}
\operatorname{Pr}\left\{X_{s}=0 \mid X_{k}=0\right\}=\gamma_{s k} \cdot(1-\lambda)+\gamma_{s k} \cdot \lambda+\left(1-\gamma_{s k}\right) \cdot(1-\lambda) \\
\left.=\gamma_{s k} \cdot \lambda+1-\lambda\right), \text { i.e. }
\end{aligned} \\
& \begin{array}{l}
\left.P_{00}=\gamma_{s k} \cdot \lambda \cdot(1-\lambda)+1-\lambda\right)^{2} \\
P_{01}=\operatorname{Pr}\left\{X_{k}=0\right\} * \operatorname{Pr}\left\{X_{s}=1 \mid X_{k}=0\right\}
\end{array} \\
& \operatorname{Pr}\left\{X_{k}=0\right\}=1-\lambda \\
& X_{s, t}=1 \text { when } X_{k, t}=0 \text { only if } V_{s k, t}=0 \text { and } U_{s, t}=1, \text { hence } \\
& \operatorname{Pr}\left\{X_{s}=1 \mid X_{k}=0\right\}=\left(1-\gamma_{s k}\right) \lambda \\
& P_{01}=\cdot(1-\lambda) \cdot\left(1-\gamma_{s k}\right) \lambda
\end{aligned}
$$

In an analogous way one finds $P_{10}$ and $P_{01}$ :

$$
\begin{aligned}
& P_{10}=\lambda \cdot(1-\lambda) \cdot\left(1-\gamma_{s k}\right) \\
& P_{11}=\lambda \cdot(1-\lambda) \cdot \gamma_{s k}+\lambda^{2}
\end{aligned}
$$

which substituted in (A3.9) yield the following expression of lag-0 correlation coefficients between two sites one of which is the key site for the other: 
$\rho_{s k}=\frac{\gamma_{s k} \lambda(1-\lambda)\left[\Delta \mu^{(k)} \Delta \mu^{(s)}+\left(\sqrt{1-\rho_{s}^{\prime 2}} \sqrt{1-\rho_{k}^{\prime 2}}+\rho_{s}^{\prime} \rho_{k}^{\prime}\right) \Delta \sigma^{(k)} \Delta \sigma^{(s)}\right]+\left(\sqrt{1-} \rho_{s}^{\prime 2} \sqrt{1-\rho_{k}^{\prime 2}}+\rho_{s}^{\prime} \rho_{k}^{\prime}\right)\left[\lambda\left(\sigma_{0}^{(s)} \sigma_{1}^{(k)}+\sigma_{1}^{(s)} \sigma_{0}^{(k)}\right)+(1-2 \lambda) \sigma_{0}^{(s)} \sigma_{0}^{(k)}-\lambda^{2} \Delta \sigma^{(k)} \Delta \sigma^{(s)}\right]}{\sigma_{s} \sigma_{k}}$

where

$$
\begin{aligned}
& \Delta \mu^{(k)}=\mu_{0}^{(k)}-\mu_{1}^{(k)} \\
& \Delta \mu^{(s)}=\mu_{0}^{(s)}-\mu_{1}^{(s)} \\
& \Delta \sigma^{(s)}=\sigma_{0}^{(s)}-\sigma_{1}^{(s)} \\
& \Delta \sigma^{(k)}=\sigma_{0}^{(k)}-\sigma_{1}^{(k)}
\end{aligned}
$$

\section{References}

Benjamin, J.R., Cornell, C.A., 1970. Probability, Statistics and Decision for Civil Engineers. McGraw-Hill, New York.

Box, G.E., Jenkins, G., 1976. Time Series Analysis, Forecasting and Control. Holden-Day, Oakland, California.

Bras, R.L., Rodriguez Iturbe, I., 1993. Random Functions and Hydrology. Dover Publications, New York.

Chebaane, M., Salas, J.D., Boes, D.C., 1995. Product periodic autoregressive processes for modeling intermittent monthly streamflows. Water Resources Research 31 (6), 1513-1518.

Claps, P., Rossi, F., Vitale, C., 1993. Conceptual-stochastic modeling of seasonal runoff using autoregressive moving average models and different scales of aggregation. Water Resources Research 29 (8), 25452559.

Dracup, J.A., Seong Lee, K., Paulson Jr., E.G., 1980a. On the statistical characteristics of drought events. Water Resources Research 16 (2), 289-296.

Dracup, J.A., Seong Lee, K., Paulson Jr., E.G., 1980b. On the definition of droughts. Water Resources Research 16 (2), 297-302.

Frevert, D.K., Cowan, M.S., Lane, W.L., 1989. Use of stochastic hydrology in reservoir operation. Journal of Irrigation and Drainage Engineering ASCE 115 (3), 334-343.

Frick, D.M., Bode, D., Salas, J.D., 1990. Effect of drought on urban water supplies. I: Drought analysis. Journal of Hydraulic Engineering ASCE $116(6), 733-753$.

Gottschalk, L., 1976. Frequency of dry years, Bullettin Series A, No. 55, University of Lund, Tenth anniversary, Lund, Sweden.

Güven, O., 1983. A simplified semiempirical approach to probabilities of extreme hydrologic droughts. Water Resources Research 19 (1), 441453.

Jackson, B.B., 1975. Markov mixture models for drought length. Water Resources Research 16 (2), 64-74.

Lee, K.S., Sadeghipour, J., Dracup, J.A., 1986. An approach for frequency analysis of multiyear drought durations. Water Resources Research 22 (5), 655-662.

Loucks, D.P., Stedinger, J.R., Haith, D.A., 1981. Water Resources Systems Planning and Analysis. Prentice Halls, Englewood Cliffs, New York.
Mariotti, A., Zeng, N., Lau, K.M., 2002. Euro-Mediterranean rainfall and ENSO - a seasonally varying relationship. Geophysical Research Letters 29 (12), 591-594.

Mazzola, M.R., Arena, C., Di Leonardo, V., 1999. The management of water resources during drought in southern Italy. In: Cabrera, E., Garcia Serra, J. (Eds.), Drought Management Planning in Urban Areas. Kluwer Academic Press.

Millan, J., Jevjevich, V., 1971. Probabilities of observed droughts, Hydrology Paper 50, Colorado State University, Fort Collins.

Paulson, E.G., Sadeghipour, J., Dracup, J.A., 1985. Regional drought frequency analysis of multiyear drought using watershed and climatic information. Journal of Hydrology 77, 57-76.

Salas, JD., 1993. In: Maidment, D.R. (Ed.), Analysis and Modelling of Hydrologic Time Series in Handbook of Hydrology. Mc Graw-Hill.

Salas, J.D., Obeysekera, J.T.D., 1992. Conceptual basis of seasonal streamflows time series models. Journal Hydraulic Engineering ASCE 118, 1186-1194.

Salas, J.D., Delleur, J.W., Yevjevich, V., Lane, W.L., 1980. Applied Modeling of Hydrologic Time Series. Water Resources Publications, Littleton, Colorado.

Santos, M.A., 1983. Regional droughts: a stochastic characterization. Journal of Hydrology 66, 183-211.

Silverman, B.W., 1986. Density Estimation for Statistics and Data Analysis. Chapman and Hall, London.

Srikanthan, R., McMahon, T.A., 1985. Recurrence interval of drought events through stochastic analysis of rainfall and streamflow data. Hydrological Sciences Journal 30, 197-206.

Srikanthan, R., McMahon, T.A., 2001. Stochastic generation of annual, monthly and daily climate data: a review. Hydrology and Earth System Sciences 5 (4), 653-670.

Stedinger, J.R., Lettenmaier, D.P., Vogel, R.M., 1985. Multisite $\operatorname{ARMA}(1,1)$ and disaggregation models for annual streamflow generation. Water Resources Research 21 (4), 497-509.

Straziuso, E., Claps, P., Fiorentino, N., 1998. Un modello per la generazione di deflussi contemporanei a scala mensile. In: Proceedings of the XXVI Convegno di Idraulica e Costruzioni idrauliche, Catania, Italy.

Thyer, M., Kuczera, G., 2000. Modeling long-term persistence in hydroclimatic time series using a hidden state Markov model. Water Resources Research 36 (11), 3301-3310.

Thyer, M., Kuczera, G., 2003a. A hidden Markov model for modelling long-term persistence in multi-site rainfall time series 1. Model calibration using a Bayesian approach. Journal of Hydrology 275, $12-26$.

Thyer, M., Kuczera, G., 2003b. A hidden Markov model for modelling long-term persistence in multi-site rainfall time series 2. Real data analysis. Journal of Hydrology 275, 27-48.

Yevjevich, V., 1967. An objective approach to definitions and investigations of continental hydrologic droughts. Hydrology Paper 23, Colorado State University, Fort Collins. 